\title{
Neuromuscular Development in the Absence of Programmed Cell Death: Phenotypic Alteration of Motoneurons and Muscle
}

\author{
Robert R. Buss, ${ }^{1}$ Thomas W. Gould, ${ }^{1}$ Jianjun Ma, ${ }^{2}$ Sharon Vinsant, ${ }^{1}$ David Prevette, ${ }^{1}$ Adam Winseck, ${ }^{1}$ \\ Kimberly A. Toops, ${ }^{1}$ James A. Hammarback, ${ }^{1}$ Thomas L. Smith, ${ }^{2}$ and Ronald W. Oppenheim ${ }^{1}$ \\ ${ }^{1}$ Department of Neurobiology and Anatomy, The Neuroscience Program, and ${ }^{2}$ Department of Orthopaedic Surgery, Wake Forest University School of \\ Medicine, Winston-Salem, North Carolina 27157
}

\begin{abstract}
The widespread, massive loss of developing neurons in the central and peripheral nervous system of birds and mammals is generally considered to be an evolutionary adaptation. However, until recently, models for testing both the immediate and long-term consequences of preventing this normal cell loss have not been available. We have taken advantage of several methods for preventing neuronal death in vivo to ask whether rescued neurons [e.g., motoneurons (MNs)] differentiate normally and become functionally incorporated into the nervous system. Although many aspects of MN differentiation occurred normally after the prevention of cell death (including the expression of several motoneuron-specific markers, axon projections into the ventral root and peripheral nerves, ultrastructure, dendritic arborization, and afferent axosomatic synapses), other features of the neuromuscular system (MNs and muscle) were abnormal. The cell bodies and axons of MNs were smaller than normal, many MN axons failed to become myelinated or to form functional synaptic contacts with target muscles, and a subpopulation of rescued cells were transformed from $\alpha$ - to $\gamma$-like MNs. Additionally, after the rescue of MNs in myogenin glial cell line-derived neurotrophic factor (MyoGDNF) transgenic mice, myofiber differentiation of extrafusal skeletal muscle was transformed and muscle physiology and motor behaviors were abnormal. In contrast, extrafusal myofiber phenotype, muscle physiology, and (except for muscle strength tests) motor behaviors were all normal after the rescue of MNs by genetic deletion of the proapoptotic gene Bax. However, there was an increase in intrafusal muscle fibers (spindles) in Bax knock-out versus both wild-type and MyoGDNF mice. Together, these data indicate that after the prevention of MN death, the neuromuscular system becomes transformed in novel ways to compensate for the presence of the thousands of excess cells.
\end{abstract}

Key words: motoneurons; spinal cord; muscle; embryo; cell death; development

\section{Introduction}

Programmed cell death (PCD) occurs during nervous system development in many animal phyla and is especially prominent and well documented in the mammalian and avian nervous system, where in many cases $50 \%$ or more of the originally generated neuronal population undergo PCD (Oppenheim, 1991; Buss et al., 2006). One popular hypothesis for the production of excess neurons is that this results in a competition for contacts with cellular partners and, thus, adjusts their numbers to provide optimum innervation of synaptic targets (Hamburger and Oppenheim, 1982; Pettmann and Henderson, 1998). Although this

Received Aug. 15, 2006; revised 0ct. 27, 2006; accepted 0ct. 30, 2006.

This work was supported by National Institutes of Health Grants NS20402 and NS048982, by a grant from the Robert Packard Center for ALS Research at Johns Hopkins University to R.W.O., and by the Mr. and Mrs. A. Tab Williams Jr and Family Neuroscience Research and Program Development Endowment. R.R.B. is a Canadian Institutes of Health Research Fellow. We thank Eric Hudgins, Luke Treloar, Carol Mansfield, and Eileen Martin for help in data collection and Judy Brunso-Bechtold, Carol Milligan, and Susan Shefchyk for use of equipment.

Correspondence should be addressed to Ronald W. Oppenheim, Department of Neurobiology and Anatomy, The Neuroscience Program, Wake Forest University School of Medicine, Winston-Salem, NC 27157. E-mail: roppenhm@wfubmc.edu.

DOl:10.1523/JNEUROSCI.3528-06.2006

Copyright $\odot 2006$ Society for Neuroscience $\quad$ 0270-6474/06/2613413-15\$15.00/0 systems-matching hypothesis has withstood considerable experimental scrutiny, it does not explain why PCD is so prominent in the developing avian and mammalian motor system, yet nearly absent in many other animals (Buss et al., 2006), or why an initially large population of neurons is necessarily functionally maladaptive. Since the initial realization that PCD is a natural developmental process, there has been an increasing interest in elucidating its molecular regulation, but less interest in its biological utility. An excess of trophic molecules (Oppenheim, 1996; Oppenheim et al., 2000), the arrest of embryonic movements by neuromuscular activity blockade (Houenou et al., 1990; Oppenheim, 1991; Oppenheim et al. 2000; Misgeld et al. 2002; Terrado et al., 2001; Brandon et al., 2003), and genetic perturbation of apoptotic biochemical pathways (Knudson et al., 1995; White et al., 1998; Sun et al., 2003; Jacob et al., 2005) have all been shown to significantly reduce or completely prevent developmental PCD of select neuronal populations, including motoneurons (MNs).

However, the developmental fate of the excess neurons has surprisingly received little attention; surprising because a better understanding of the development of rescued neurons could reveal additional clues to the necessity and biological significance of 
developmental PCD. We examined the development of several animal models that develop with reduced PCD in the motor system to determine whether the excess MNs project to their normal targets, develop, and grow into normal MNs or atrophy, and whether classes of MNs (e.g., $\alpha$ vs $\gamma$, fast vs slow,) are differentially affected by PCD. These models include the Bax knock-out (KO) mouse (Knudson et al., 1995), the MyoGDNF mouse (Nguyen et al., 1998), the paralytic choline acetyltransferase (ChAT) KO mouse (Brandon et al., 2003), and the pharmacologically paralytic chick embryo (Pittman and Oppenheim, 1978, 1979; Oppenheim and Chu-Wang, 1983).

\section{Materials and Methods}

Animals and genotyping. Bax-mutant mice (Knudson et al., 1995) were maintained on a C57BL/6J background. MyoGDNF mice (Nguyen et al., 1998) from a B6/CBA background that had been outbred were backcrossed for at least five generations to $\mathrm{C} 57 \mathrm{BL} / 6 \mathrm{~J}$ mice following the recommendations of the Banbury conference on genetic background in mutant mice (Silva, 1997). Unless noted, all experiments were performed on adult male and female mice between 6 months and 1 year of age on a C57BL/6J background. All experiments were conducted following guidelines established by the Institutional Animal Care Committee of Wake Forest University School of Medicine (Winston-Salem, NC). Interbreeding of offspring derived from a cross of Bax+/- mice (Knudson et al., 1995) with MyoGDNF mice (Nguyen et al., 1998) are referred to as the outbred C57BL/6J $\times$ B6/CBA background. Bax-mutant and MyoGDNF mice were genotyped (Knudson et al., 1995; Nguyen et al., 1998) and ChAT- and GDNF receptor family $\alpha(\mathrm{GFR} \alpha)$-mutant mice (Enomoto et al., 1998; Brandon et al., 2003) were both genotyped and phenotyped by the absence of movements and kidneys, respectively. With the exception of the phrenic nerve (see Results), similar changes in myelinated axon numbers were observed when the Bax $\mathrm{KO}(-/-)$ and MyoGDNF transgenic mice were maintained on C57BL/6J or on outcrossed C57BL/6J $\times$ B6/CBA backgrounds.

Chick embryos were from eggs of a White Leghorn strain (Tyson Foods, Wilkesboro, NC). Chick embryos were paralyzed with (+)tubocurarine (Sigma, St. Louis, MO) applied daily from embryonic days 6-9 (E6-E9) at $2.5 \mathrm{mg} / \mathrm{d}$ or from E10-E16 at $1.5 \mathrm{mg} / \mathrm{d}$. Acute paralysis refers to chicks treated with (+)-tubocurarine from E6-E9, and chronic paralysis to those treated from E6-E16; both groups were killed at E17. Movements were monitored daily to confirm paralysis (Pittman and Oppenheim, 1979) and cell counts verified reduced MN PCD (Clarke and Oppenheim, 1995).

Morphometric analysis, immunochemistry, histochemistry and SDSPAGE. E15 mouse and E10 and E17 chick embryos processed for paraffin embedding were immersion fixed in Bouin's solution. All other tissue was perfusion fixed in either Bouin's solution (paraffin embedding and thionin staining), 2-4\% paraformaldehyde in PBS (antibody labeling and Golgi staining), or $2 \%$ paraformaldehyde $/ 2 \%$ glutaraldehyde in cacodylate buffer with postfixing in $2 \%$ osmium tetroxide (plastic embedding for toluidine blue staining or processing for electron microscopy).

The FD Rapid GolgiStain kit (FD Neurotechnologies, Baltimore, MD) was used for Golgi staining. The density of Golgi-stained ventral horn dendrites was determined by tracing (camera lucida) all Golgi-labeled dendrites in transverse sections of the neuropil of the midlumbar ventral horn at a magnification $(200 \times)$ that allowed visualization of the entire ventral horn; processes in the adjacent lateral and ventral white matter were excluded. The dendritic density was estimated by the average pixel density of digital images. For each animal, 10 sections were analyzed in this way. Anti- $\alpha 3 \mathrm{Na}^{+} / \mathrm{K}^{+}$ATPase $(\alpha 3 \mathrm{NKA}$; Upstate Biotechnology, Lake Placid, NY) to label putative $\gamma$-MN axons was used as described previously (Dobretsov et al., 2003). Paraffin-embedded cross sections (15 $\mu \mathrm{m}$ thick) through the L4 ventral root (VR) and the buccal branch of the facial nerve were labeled with $\alpha 3$ NKA or neurofilament-heavy chain (NF-H; Millipore, Temecula, CA) and the total number of $\alpha 3 \mathrm{NKA}-$ positive profiles were counted in each of three sections separated by 75 $\mu \mathrm{m}$. For counting synapses in the medial gastrocnemius muscle of adult mice [postnatal day 100-150 (P100-P150)], consecutive 40- $\mu$ m-thick cross sections of paraformaldehyde-fixed sucrose embedded muscle were cut and stained with antibodies against synaptophysin (Dako, High Wycombe, UK) or neurofilament-light chain (Millipore) as presynaptic markers and cyanine $3(\mathrm{Cy} 3)$-conjugated $\alpha$-bungarotoxin as a postsynaptic marker. All profiles exhibiting colocalization of presynaptic and postsynaptic markers in sections through the entire muscle were included in the counts. Fast DiI (Invitrogen, Eugene OR) was applied to the phrenic nerve in fixed tissue to retrogradely label phrenic MNs. DiIlabeled phrenic MN numbers were estimated by counting every second $14-\mu \mathrm{m}$-thick section through the phrenic motor nucleus and multiplying these values by two. Whole mounts of E15 diaphragm muscle of wild-type (WT) $(n=2)$ and Bax KO mice $(n=2)$ were examined for innervation and synapse formation using anti-NF-H and $\mathrm{Cy} 3-\alpha \mathrm{BTX}$ as described by Brandon et al. (2003).

After anesthetizing 6-month-old adult Bax WT and KO mice with ketamine/xylazine, 3-4 unilateral injections of the retrograde tracer Fluorogold (total volume $3 \mu \mathrm{l}$ of a $4 \%$ solution; Fluorochrome, Denver, CO) were made into the whisker pads. Seven days after injection, the animals were killed and the hindbrains immersion-fixed in $4 \%$ paraformaldehyde at $4^{\circ} \mathrm{C}$ overnight, embedded in $30 \%$ sucrose cryopreserved in $3: 2$ sucrose:OCT cryopreservation compound (Ted Pella, Redding, CA), and transverse sections cut at $16 \mu \mathrm{m}$ on a cryostat at $-30^{\circ} \mathrm{C}$. Every fifth section through the facial nucleus was incubated with RNase A (400 $\mathrm{mg} / \mathrm{ml}$; Roche, Indianapolis, IN) for $30 \mathrm{~min}$ at $37^{\circ} \mathrm{C}$ and stained for $5 \mathrm{~min}$ at room temperature with propidium iodide ( $10 \mu \mathrm{g} / \mathrm{ml}$; Sigma) to visualize nuclei. After rinsing in PBS and mounting (Gelmount; Biomeda, Foster City, CA), the number of Fluorogold-labeled MNs with a complete nuclear membrane and at least one nucleolus were counted and the totals multiplied by five. Human recombinant GDNF was a gift from Amgen (Thousand Oaks, CA). Myosin heavy chain isoforms were identified by SDS-PAGE as described by Serrano et al. (1996). Gels were stained with Sypro Ruby Gel Stain (Invitrogen) and the myosin isoforms quantified using a Typhoon 8600 imager (GE Healthcare Bio-Sciences, Piscataway, NJ); all measurements were made within the linear range of this assay. Myofibrillar ATPase histochemistry was performed on frozen sections of the gastrocnemius muscle as described by Guth and Samaha (1970) and Serrano et al. (1996) after acid and alkaline preincubation. A range of $\mathrm{pH}$ values was used for fiber type identification (type I, IIa, IIb).

Thionin- or Golgi-stained somas were traced using a camera lucida, scanned, and cross-section areas measured using Scion (Frederick, MD) Image software. Because cross-sectional area measurements underestimated cell size changes (for example, transforming cell area to cell volume changes a $21 \%$ area decrease to a $29 \%$ volume decrease in comparing adult $\mathrm{Bax} \mathrm{KO}$ to $\mathrm{WT}$ ), we used cell volume for all soma size measurements. Counts and measurements of myelinated axons were taken from montages of central or peripheral nerves digitally photographed through a $100 \times$ oil immersion objective and assembled using Adobe (San Jose, CA) Photoshop software. Muscle was photographed through a $40 \times$ objective, myofiber outlines manually traced, scanned, and cross-sectional areas measured using Scion Image software; myofiber counts and diameter measurements were done manually using Scion Image software. Muscle spindles were counted by following individual spindles through $1-\mu \mathrm{m}$-thick serial sections taken every 60 or $120 \mu \mathrm{m}$, through the entire medial gastrocnemius muscle. Muscle spindles were easily identified as encapsulated bundles of small muscle fibers with nerve fibers in close proximity. Counts of unmyelinated axons were done directly in the electron microscope for adult nerves or from micrographs $(3150-8000 \times)$ that were scanned and assembled into montages of the complete nerve using Adobe Photoshop software for P0 nerves. Axon measurements and counts were done manually with Scion Image software.

To quantify motoneuron (MN) synapse density, three adult WT and three Bax $\mathrm{KO}(-/-)$ mice were perfused intracardially after an overdose of ketamine/xylazine with $2 \%$ glutaraldehyde, $2 \%$ paraformaldehyde in 0.13 м sodium cacodylate buffer, $\mathrm{pH}$ 7.4, using a peristaltic pump at a flow rate of $10 \mathrm{ml} / \mathrm{min}$. Lumbar spinal cord was dissected via dorsal laminectomy and placed in fix overnight at $4^{\circ} \mathrm{C}$ then embedded in $4 \%$ low-temperature melting agarose and cut at $300 \mu \mathrm{m}$ on a vibratome. The L4 ventral horn was dissected out based on the rostral/caudal location determined from previous DiI labeling experiments. Specimens were 
osmicated and embedded in Araldite 502 plastic (Ted Pella, using a Lynx tissue processor. Sections were cut using an LKB/Leica (Vienna, Austria) ultramicrotome. One-micrometer-thick sections were stained with toluidine blue and then photographed. MNs containing a clear nucleus and nucleolus were identified and adjacent thin sections ( $700 \AA$ ) were collected on formvar-coated slot grids, stained with lead citrate and methanolic uranyl acetate, and subsequently mapped out using the $\mathrm{X} / \mathrm{Y}$ stage coordinates of a Zeiss (Oberkochen, Germany) EM 10. After mapping the section, the locations of MNs identified in the adjacent thick sections were marked. The selected MNs were photographed at $1600 \times$ and the number of axosomatic synapses around the entire MN soma was counted at $10,000 \times$. A synapse was defined as a density on the postsynaptic membrane accompanied by a presynaptic bouton containing synaptic vesicles. The perimeter and area of each MN were measured from the micrographs using Scion Image, and the numbers of synapses $/ 10 \mu \mathrm{m}$ were derived. MNs were classified as either $\alpha$-MN-like or $\gamma$-MN-like based on size (area): $\alpha$-MN $>400 \mu \mathrm{m}^{2} ; \gamma-\mathrm{MN}<400 \mu \mathrm{m}^{2}$. ANOVA statistical analysis was performed using Statistics 6.0 (Statsoft, Tulsa, OK).

Muscle physiology. For muscle physiology experiments, 2- to 3-monthold mice were anesthetized with isofluorane and normal body temperature was maintained with a heat lamp. Suprathreshold stimuli (single shock for twitch and $150 \mathrm{~Hz}$ for tetanus) were applied to the sciatic nerve and gastrocnemius muscle force was measured using a Grass FT03 force transducer. Stimuli at thresholds sufficient to activate unmyelinated axons did not lead to additional force production. Measurements were taken from chart recordings [Gould (Harvard Apparatus, Holliston, MA) RS3800] collected at $100 \mathrm{~mm} / \mathrm{s}$ (twitch) or $10 \mathrm{~mm} / \mathrm{s}$ (tetanus).

Behavioral tests. Adult mice were examined in five different behavioral tasks designed to test motor coordination, balance, and muscle strength. All tests were conducted during the normal light cycle (i.e., between 8:00 A.M. and 10:00 A.M.). They were given $3 \mathrm{~d}$ of exposure and training (5-10 min per day per test) before testing and data collection began on day four. In the rotorod test, mice were placed on the rotating drum of an AccuRotor Rota Rod (Accuscan, Columbus, $\mathrm{OH}$ ) at 2-3 rpm. The drum gradually increased speed over $5 \mathrm{~min}$ up to a maximum of $40 \mathrm{rpm}$ and the average speed attained before falling was recorded. The hole board consisted of $20 \times 20$ inch board with $25 \mathrm{~mm}$ diameter holes 1 inch apart. Mice were placed in the center and allowed $3 \mathrm{~min}$ to explore and the number of times a foot fell into a hole was recorded. In the balance beam test, mice were given three trials to cross each of three different sized (diameter) beams $(20,15$, and $10 \mathrm{~cm})$ that were $55 \mathrm{~cm}$ long and provided a dark escape enclosure at one end. The proportion of animals in each group that crossed successfully within 2 min without slipping or falling was recorded. Grip strength was assessed using a Pesola (Baar, Switzerland) spring scale with a grip bar calibrated up to $100 \mathrm{~g}$. Each animal was tested for forelimb grip strength while holding the grip bar on a table top and being gently pulled by the tail. The hanging wire test was as described by Kong and Xu (1998). Mice were allowed to hang on to a vertical wire with a loop at the end with their forelimbs or with both forelimbs and hindlimbs and were rotated in the air at 15-20 rpm and the time to release and falling a few inches to a padded table top was recorded.

All statistical analyses were performed using either the Student's $t$ test, with the Bonferroni correction or ANOVA. All anatomical, physiologi$\mathrm{cal}$, and behavioral analyses were performed without knowledge of the genotype or treatment of the individual animals (i.e., blinded).

\section{Results}

\section{Motoneurons rescued from PCD project axons to target muscles}

During normal development, postmitotic MNs project to their muscle targets and either survive or undergo PCD; the survivors grow, differentiate, and their axons become myelinated. Previous studies of motor systems developing with reduced PCD have reported more cell bodies in central motor nuclei or more axons in cranial or spinal roots (Sun et al., 2003), but with the exception of paralytic chicks and mice (Ding et al., 1983; Oppenheim and Chu-Wang, 1983; Landmesser, 1992; Misgeld et al., 2002), whether rescued MNs project to their muscle targets has not been
Table 1. Number of myelinated axons in adult mice and E17 chickens that developed with normal or reduced programmed cell death

\begin{tabular}{|c|c|c|c|}
\hline Adult mouse & Wild type & Bax knock-out & MyoGDNF \\
\hline Abducens & $221 \pm 44(5)$ & $317 \pm 66(5)$ & $336 \pm 52(4)$ \\
\hline Oculomotor & $761 \pm 55(6)$ & $1117 \pm 84(5)$ & $793 \pm 100(5)$ \\
\hline Trochlear & $115 \pm 30(6)$ & $183 \pm 29(5)$ & $144 \pm 22(5)$ \\
\hline Spinal accessory & $362 \pm 39(5)$ & $806 \pm 112(5)$ & $611 \pm 53(5)$ \\
\hline Buccal $^{a}$ & $694 \pm 91(12)$ & $1248 \pm 154(10)$ & n.d. \\
\hline Ventral root $(\mathrm{L} 4)^{a}$ & $1082 \pm 48(12)$ & $1847 \pm 204(11)$ & $2015 \pm 291(8)$ \\
\hline Quadriceps & $559 \pm 75(12)$ & $764 \pm 58(10)$ & $728 \pm 104(4)$ \\
\hline L. Gastrocnemius soleus $^{a}$ & $191 \pm 13(10)$ & $271 \pm 12(11)$ & $274 \pm 43(5)$ \\
\hline M. Gastrocnemius ${ }^{a}$ & $128 \pm 15(10)$ & $187 \pm 16(7)$ & $196 \pm 16(5)$ \\
\hline Phrenic & $257 \pm 21(12)$ & $318 \pm 32(11)$ & $271 \pm 27(3)$ \\
\hline Dorsal root (L4) & $2475 \pm 145(10)$ & $3113 \pm 296(9)$ & $2464 \pm 212(10)$ \\
\hline Saphenous $^{a}$ & $811 \pm 61(12)$ & $913 \pm 73(10)$ & $715 \pm 144(4)$ \\
\hline E17 chicken & Control & Acute paralysis & Chronic paralysis \\
\hline Ventral root & $2164 \pm 270(9)$ & $3303 \pm 662(3)$ & $3149 \pm 505(6)$ \\
\hline Dorsal root & $2097 \pm 179(6)$ & $1777 \pm 368(5)$ & $1606 \pm 382(6)$ \\
\hline Gastrocnemius & $685 \pm 70(6)$ & $970 \pm 33(2)$ & n.d. \\
\hline
\end{tabular}

All mouse data are from C57BL6/J background strain. Values shown are mean \pm SD (number of animals is in parentheses). n.d., Not determined. For statistics, see Figure 1.

${ }^{a}$ Numbers of myelinated axons were examined in the outbred C57BL6/J $\times B 6 / C B A$ strain and significant differences similar to those observed in the $C 57 \mathrm{BL} 6 / \mathrm{J}$ strain were observed (4-7 animals per group).

systematically examined (Sun et al., 2003; Jacob et al., 2005). In cross sections of adult peripheral hindlimb and cranial nerves (mixed motor and sensory) of Bax KO and MyoGDNF mice (and in the paralyzed embryonic chick), we observed more $(\sim 40-$ $50 \%$ ) myelinated axons in close proximity to their muscles compared with WT mice or vehicle-treated chick embryos (Table 1, Fig. 1). Exceptions were found in the oculomotor nerve and the buccal nerve (a branch of the facial nerve that innervates the whisker pad muscles) of MyoGDNF mice in which little if any rescue from PCD has been observed (Oppenheim et al., 2000; Whitehead et al., 2005), and in the phrenic nerve where the response was strain dependent. Counts of myelinated axons in peripheral muscle nerves could not reveal whether the increased numbers were caused by expanded sensory (myelinated proprioceptive afferents) or motor populations. To discriminate between the two, axon counts were compared in pure motor (L4 ventral root and buccal nerve) and pure sensory (L4 dorsal root) nerves. Neither neuromuscular paralysis (paralytic chick embryo) nor development with excess GDNF (MyoGDNF mouse) resulted in increased numbers of myelinated sensory axons $(\mathrm{Ta}-$ ble 1, Fig. 1), indicating that the increases observed in peripheral muscle nerves were entirely attributable to MNs. More myelinated sensory dorsal root axons ( $28 \%$ increase) were present in the $\mathrm{Bax} \mathrm{KO}$, but this increase was not as great as observed in the pure motor ventral root $(71 \%$ increase $)$ and is consistent with the intermediate increases (37-46\% increase) we observe in mixed hindlimb nerves (Table 1, Fig. 1). There was only a small increase $(13 \%)$ in myelinated cutaneous afferents (saphenous nerve) (Table 1, Fig. 1) indicating that the majority of supernumerary myelinated sensory neurons in the Bax KO must have been proprioceptive (Wright et al., 1997; Taylor et al., 2001a,b; Patel et al., 2003).

Fluorogold injections into the whisker pads labeled significantly more facial MNs in the Bax KO (30\%; $<$ < 0.01) (data not shown), suggesting that many of the excess facial MNs innervated their targets (see also Jacob et al., 2005). Although the significant increase in retrogradely labeled facial MNs in the Bax KO suggests that many rescued cells may have formed synaptic contacts, because we did not attempt to directly quantify neuromuscular 
synapses in the whisker pad we cannot exclude the alternative possibility that axons in close proximity but not in synaptic contact with the muscle may have nonetheless taken up and transported the tracer. However, the fact that both large- and smallsized facial MNs were retrogradely labeled indicates that the rescued MNs must have axons in close proximity to the whiskerpad muscles and that even the small-sized axons have an intact retrograde transport system.

It is interesting that whereas the complete rescue of MNs from developmental PCD by neuromuscular activity blockade in avian and mammalian embryos results in a striking increase in intramuscular axon branching and synapse numbers (Landmesser, 1992; Misgeld et al., 2002; Brandon et al., 2003), this was not the case in Bax KO/or MyoGDNF embryos (data not shown).

To determine the phenotype of rescued $\mathrm{MNs}$, we first examined the size distribution of axons in ventral roots and muscle nerves. The physiological function of MNs corresponds closely with their size, the largest MNs $(\alpha)$ innervate movementproducing extrafusal muscle fibers and the smallest MNs $(\gamma)$ innervate intrafusal muscle fibers and regulate the sensitivity of proprioceptive muscle spindle organs (Burke, 1981; Henneman and Mendell, 1981; Matthews, 1981). Within the $\alpha$ class of MNs, size correlates with the type of motor unit and muscle fiber innervated. Examination of pure motor ventral roots revealed a striking increase in the number of small myelinated axons in both Bax KO and MyoGDNF versus WT mice (Fig. $2 A-C)$ and an increase in small- to medium-sized axons in paralyzed chick

(E17) ventral roots (Fig. $2 D, E$ ). In all cases in which $M N$ number was increased, there was a decrease in axon size (mean diameter decreased by $14-39 \%)$. Although not all parts of the axon size distribution were equally affected (Fig. $2 F, G$ ), there was a general decrease in size throughout the distribution. In the Bax KO, the entire population of myelinated supernumerary axons fell into the normally smaller $\gamma$-MN size distribution $\left(<5 \mu \mathrm{m}^{2}\right)$ whereas the larger $\left(>5 \mu \mathrm{m}^{2}\right)$ myelinated $\alpha$-MN distribution was largely unaffected; in MyoGDNF mice, the excess axons were increased in both the $\gamma$ - and small $\alpha$-MN size distribution. Distinct $\alpha$ - and $\gamma$-MN populations were not present in E17 chick ventral roots, but similar to the mouse, all the excess myelinated axons in the paralyzed chick ventral roots were in the small-diameter $\alpha$-MN size class. In summary, eliminating MN PCD did not lead to increased numbers of myelinated $\mathrm{MN}$ axons in the population as a whole, but rather supernumerary axons were preferentially increased in populations in the size range of wild-type $\gamma$-MNs and small $\alpha$-MNs. All excess myelinated MN axons (L4 ventral root) in the Bax KO were in the $\gamma$-MN size class, whereas myelinated supernumerary MNs in the MyoGDNF mouse and paralytic chick were in either the small $\alpha$-MN (chick, mouse) or typical $\gamma$-MN size (mouse) classes.

Because $\mathrm{MN}$ size is associated with $\mathrm{MN}$ firing properties and recruitment (Henneman and Mendell, 1981), in general, MNs with large axon diameters have large somas and, conversely, MNs with small axon diameters have small somas. To determine whether the decrease in diameter of rescued MN axons corresponded to a similar reduction in $\mathrm{MN}$ cell body area in Bax KO and MyoGDNF mice, soma size was measured. As expected, MNs were smaller in the Bax KO and MyoGDNF mice as well as in paralyzed chick embryos (Tables 2, 3, Fig. 3). However, measurable differences in soma size were not observed until after E10 in paralyzed chicks ( 150 cells in each of three animals) (data not shown) and not until P10 in MyoGDNF mice (Tables 2, 3, Fig. $3 A$ ); MN soma size was unchanged at $\mathrm{P0}$ in ChAT KO mice, which die of asphyxia at birth (also see Terrado et al., 2001). Similar to WT mice, MN soma size increased with age in the Bax $\mathrm{KO}$ and MyoGDNF mice, but the time course of soma growth differed (Fig. 3B). Increases in soma size appeared to progress more slowly in the Bax KO before birth, partly because of an 

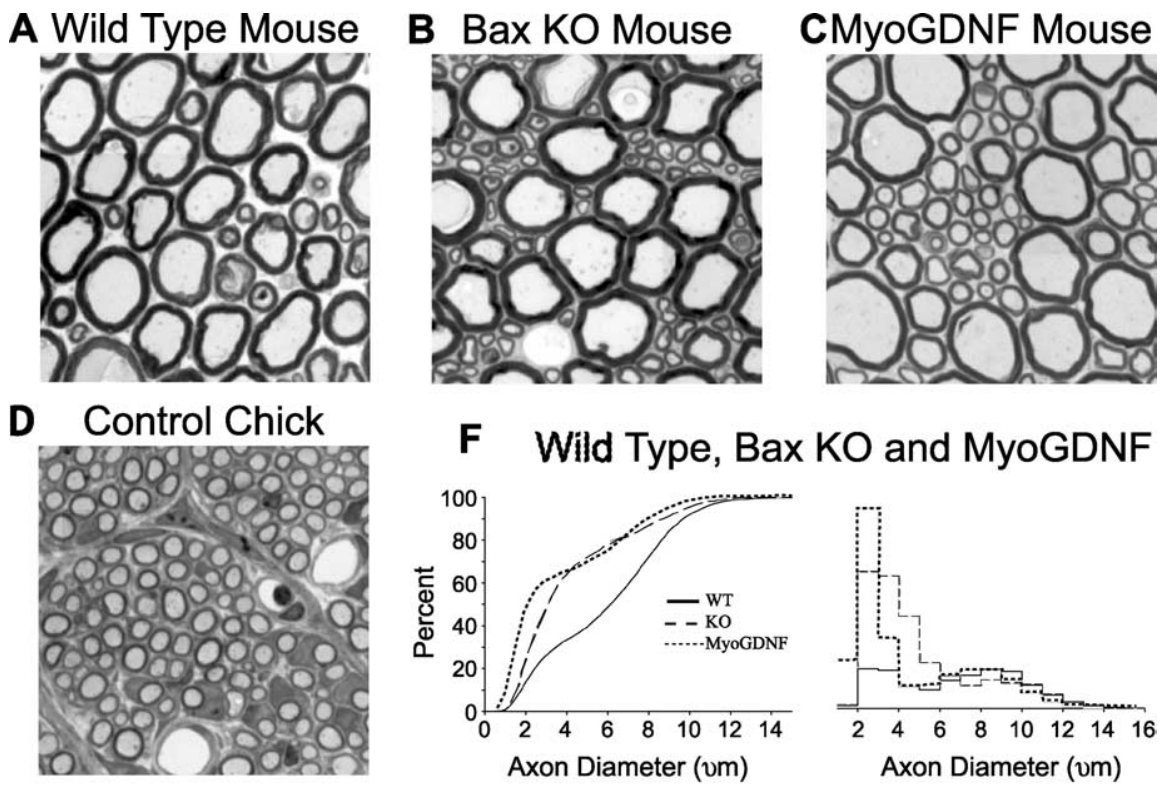

E Paralyzed Chick

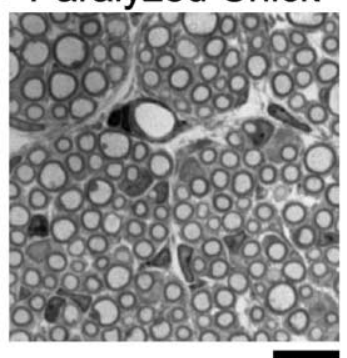

$10 \mathrm{vm}$

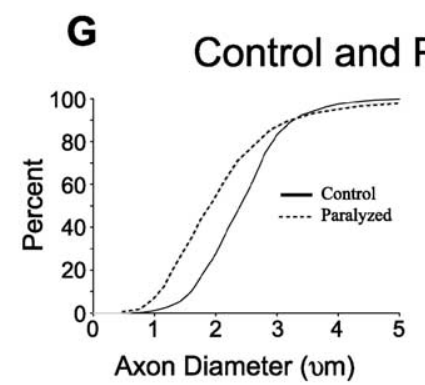

Paralyzed Chick

Figure 2. Modification of MN axon size after rescue from PCD. $\boldsymbol{A}-\boldsymbol{E}$, Ventral root (L4) axons from WT $(\boldsymbol{A})$, Bax K0 $(\boldsymbol{B})$, and MyoGDNF ( $C$ ) mice (4-5 months old) maintained on a 57 BL6/J background, and chick ventral roots from E17 control (D) and chronically paralyzed $(\boldsymbol{E})$ White Leghorn chick embryos. $\boldsymbol{F}, \boldsymbol{G}$, Cumulative probability distributions and size histograms (normalized to WT axon number) of ventral root axon diameters from mice $(\boldsymbol{F})$ and chick (G).

Table 2. MN soma size (cross-section area in micrometers squared) in mice with normal or reduced developmental cell death

\begin{tabular}{lllll}
\hline Mouse & E15 & P0 & P10 & Adult \\
\hline Wild-type & $171 \pm 44(420,7)$ & $285 \pm 137(385,7)$ & $339 \pm 183(295,5)$ & $641 \pm 311(350,7)$ \\
Bax knock-out & $151 \pm 40(300,5)$ & $172 \pm 123(330,6)$ & $279 \pm 166(236,4)$ & $508 \pm 343(500,10)$ \\
MyoGDNF & $163 \pm 48(360,6)$ & $280 \pm 124(330,6)$ & $289 \pm 159(295,5)$ & $535 \pm 273(450,9)$ \\
ChAT knock-out & & $265 \pm 110(240,4)$ & & \\
\hline
\end{tabular}

Values shown are mean \pm SD. Values in parentheses are the number of measurements, and number of animals. For statistics, see Figure 3.

Table 3. MN soma size (cross-section area in micrometers squared) in chickens with normal or reduced developmental cell death

\begin{tabular}{llll}
\hline Chicken & E17 control & E17-E6 to E9 DTC & E17-E6 to E16 DTC \\
\hline Midlumbar cord & $528 \pm 95(500,5)$ & $465 \pm 97(400,4)$ & $490 \pm 102(400,4)$ \\
Lower lumbar cord & $514 \pm 91(500,5)$ & $446 \pm 86(400,4)$ & $452 \pm 102(400,4)$ \\
\hline
\end{tabular}

Values shown are mean \pm SD. Values in parentheses are the number of measurements, and number of animals. For statistics, see Figure 3. DTC, D-Tubocurarine.

apparent atrophy (Fig. 3C) of the small size class of MNs, whereas in MyoGDNF mice, MN growth was negligible between birth and P10. Reducing PCD does not appear to result in the differentiation of a homogenous population of excess MNs, but rather, depending on the mechanism of rescue (e.g., Bax KO vs GDNF overexpression), supernumerary MNs mature at different rates and differentiate into unique size classes of MNs.

\section{Differentiation of supernumerary} motoneurons in the Bax KO

To more completely characterize the phenotype of rescued MNs, in the Bax KO, we examined molecular markers, axon projections, physiology, and behavior. Innervation of muscle fibers, assessed by counting the number of neuromuscular junctions (NMJs; formed by $\alpha$-MNs) in the medial gastrocnemius muscle, was unchanged (Table 4) and polyneuronal innervation of extrafusal muscle fibers was not observed after the normal period of synapse elimination (Sun et al., 2003) (data not shown). Golgi staining clearly labeled the dendritic trees of MNs, allowing an analysis of their structure. The number of Golgi-stained primary dendritic branches of individual Bax KO MNs appeared similar to WT (Fig. 4). In both genotypes, large MNs had increased numbers of primary dendrites versus small MNs (Fig. $4 A$ ), but the overall density of Golgi-stained dendrites within the ventral horn was unchanged (Fig. $4 B$ ).

As one measure of electrophysiological changes in $\mathrm{MN}$ function, $\alpha$-MNs were activated by electrical stimulation of the sciatic nerve and the motor action they evoked was measured by recording the force produced in the medial gastrocnemius muscle. All measures of neuromuscular activation obtained from Bax $\mathrm{KO}$ mice were indistinguishable from WT mice except for an increase in force production during tetanus stimulation in the Bax KO (Table 4). However, in the smaller sample of mice tested with tetanus stimuli, the mean twitch force was also greater in the Bax $\mathrm{KO}$, whereas in the larger sample of mice tested for twitch force and muscle mass (Table 4) no difference was observed between WT and Bax KO mice. Another measure, the tetanus/twitch ratio, which takes into account individual variation in muscle strength, was not significantly different between WT and Bax KO mice (Table 4).

Because changes in neuromuscular input can lead to changes in muscle properties (Nemeth, 1990; Floeter, 1999), we next examined whether muscle phenotype was changed in Bax KO mice. Consistent with the results of our electrophysiological analysis, we failed to observe obvious changes in muscle fiber composition (see also Sun et al. 2003). Examination of 1- $\mu$ m-thick serial sections (every $60-120 \mu \mathrm{m}$ ) of the medial gastrocnemius muscle did not reveal obvious differences in muscle fiber composition (Fig. $5 A-D$ ), size (Table 4 ), or distribution throughout the muscle (Table 4). The mixed fiber types in the head of the muscle (Fig. $5 A, C)$ and the homogenous large fiber population near the insertion of the muscle (Fig. $5 B, D$ ) were unchanged. Muscle mass (Table 4), fiber density (Table 4, Fig. 5A-D), myosin heavy chain composition (Fig. 5G), and myosin ATPase histochemistry (data not shown) were also unchanged. Therefore, together with the 
observation that the increased myelinated ventral root $\mathrm{MN}$ axons in Bax $\mathrm{KO}$ versus WT fall into smaller size categories, these results indicate that the population of large $\alpha$-MNs and the extrafusal muscle fibers that they innervate were unaffected in $B a x$ KO.

Are the small excess motoneurons with myelinated axons in the Bax KO $\alpha$ or $\boldsymbol{\gamma}$-motoneurons?

Our inability to detect anatomical or electrophysiological differences in the large $\alpha$-MN population of the Bax KO led us to propose that either (1) differences in $\mathrm{MN}$ axon number reflect a selective change (increase) in the number of $\gamma$-MNs or (2) the increase in axon number fails to translate into electrophysiological changes. For example, as suggested previously (Sun et al., 2003) and confirmed here (Table 1), the excess $\alpha$-MN axons may fail to innervate muscle targets. To distinguish between these possibilities, we first examined motor behavior and muscle spindle innervation. Observations of simple motor behaviors [beam walking, hole board walking, rotorod, grip strength, hanging wire

(Kong and Xu, 1998; Rondi-Reig et al., 1999; Crawley, 2000; Taylor et al., 2005)], some of which can reveal gross defects in proprioception that might be expected from abnormal spindle innervation (Taylor et al., 2005), revealed increased performance on the muscle strength tests but no change in tests of motor coordination or balance (Fig. 6A-E). Although these data suggest that individual muscle spindles are not aberrantly hyperinnervated by the putative increase in $\gamma$-MNs in the Bax KO, as occurs in MyoGDNF mice (Whitehead et al., 2005), it is also possible that because of muscle spindle induction by rescued proprioceptive sensory neurons (Kucera and Walro, 1992a,b; Zelena, 1994) there is an increased number of muscle spindles in the Bax KO but that each receives a normal amount of innervation from excess $\gamma$-MNs. In fact, we observed an increase in the number of innervated muscle spindles in $\operatorname{Bax} \mathrm{KO}(16.5 \pm 0.4 ; n=4)$ versus WT mice $(9.5 \pm 0.5 ; n=4 ; p<0.01, t$ test) (Fig. $7 A, B)$ consistent with the results of a previous study (Genc et al., 2004). Because muscle spindles are typically innervated by two or more MNs (Kozeka and Ontell, 1981; Matthews, 1981), even a modest increase in spindle numbers could provide significantly more target space for innervation by expanded numbers of $\gamma$-MNs in the Bax KO. The maintenance of a normal ratio of MN innervation of individual spindles despite the increased number of total spindles may explain the normal motor behavior in the Bax $\mathrm{KO}$ mice on tests of balance and coordination.

Additional evidence that many supernumerary MNs may be $\gamma$-MNs was provided by differences in the timing of axon myelination. During normal postnatal development, the myelination of $\alpha$-MN axons precedes that of $\gamma$-MNs (Fraher et al., 1988). Ventral root myelination was, in fact, protracted in the Bax KO in that a significant increase in myelinated axon number only occurred at P14 and the myelination process continued into the third week whereas it was complete by the second week in Bax WT mice (Fig. 7C). Myelination of dorsal roots in the Bax KO was not nearly as protracted (Fig. 7D) and at P7 the final percentage
B
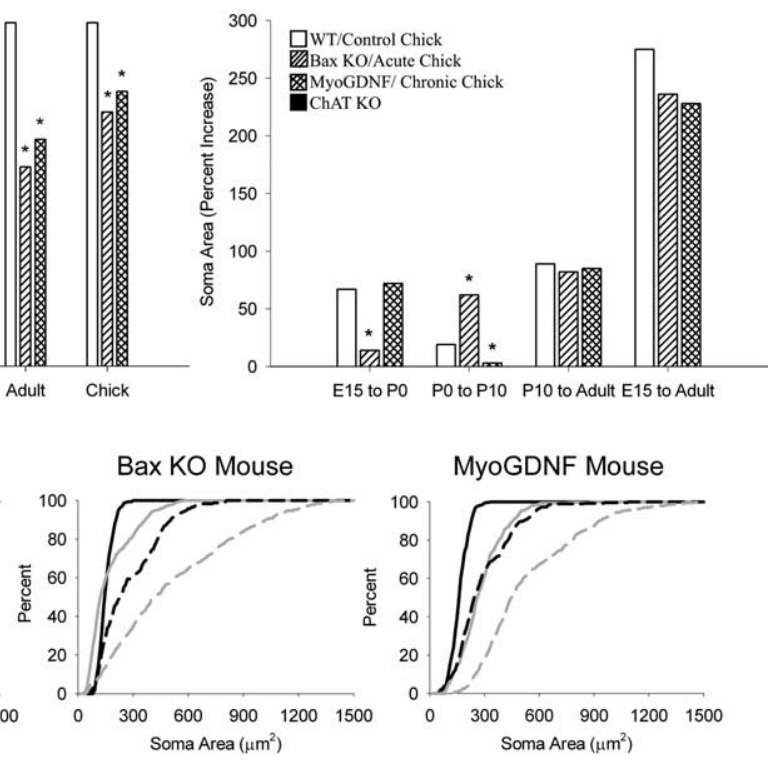

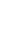

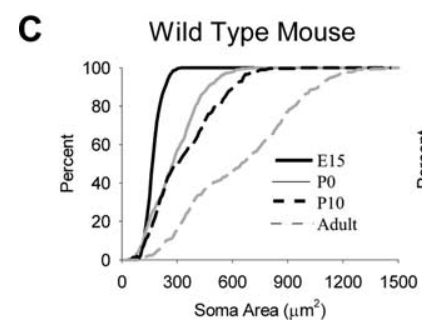

Figure 3. Modification of lumbar MN soma size and growth after rescue from PCD. $\boldsymbol{A}$, Normalized soma areas in E15, P0, P10, and adult mice and E17 chick. Soma size has been normalized to WT or control chick (open bars). $\boldsymbol{B}$, Increase in mouse MN soma mouse strain was an outbred B6/CBA $\times C 57 B L 6 / J$ line. * Significant difference $(p<0.05, t$ test) from WT or control. Means and SDs for $\boldsymbol{A}$ and $\boldsymbol{B}$ are provided in Tables 2 and 3 .

Table 4. Physiological and anatomical characteristics of wild type, Bax KO, and MyoGDNF medial gastrocnemius muscle

\begin{tabular}{lccc}
\hline & Wild type & Bax K0 & MyoGDNF \\
\hline Twitch force (mN) & $540 \pm 140(15)$ & $590 \pm 140(11)$ & $200 \pm 60(6)^{*}$ \\
Twitch rise time (ms) & $23 \pm 3(11)$ & $22 \pm 3(9)$ & $24 \pm 2(6)$ \\
Twitch half-width (ms) & $21 \pm 2(11)$ & $21 \pm 2(9)$ & $22 \pm 3(6)$ \\
Tetanus force (N) & $2.2 \pm 0.4(7)$ & $3.0 \pm 0.4(6)^{*}$ & $1.3 \pm 0.3(6)^{*}$ \\
Tetanus 50\% fatigue (s) & $1.1 \pm 0.3(7)$ & $0.9 \pm 0.4(6)$ & $2.7 \pm 1.2(6)^{*}$ \\
Tetanus/twitch & $4.9 \pm 1.2(7)$ & $5.4 \pm 1.3(6)$ & $6.6 \pm 1.4(6)$ \\
Fixed muscle mass (g) & $0.17 \pm 0.03(21)$ & $0.18 \pm 0.02(11)$ & $0.08 \pm 0.01(13)^{*}$ \\
Neuromuscular junctions & $4931 \pm 342(3)$ & $5134 \pm 449(3)$ & $4341 \pm 465(3)$ \\
Fibers/mm ${ }^{2}$ (head) & $1370 \pm 30(3)$ & $1340 \pm 70(3)$ & $2680 \pm 520(3)^{*}$ \\
Fibers/mm ${ }^{2}$ (insertion) & $880 \pm 90(3)$ & $760 \pm 100(3)$ & $2620 \pm 220(3)^{*}$ \\
Fiber size $\mu \mathrm{m}^{2}$ (head) & $83 \pm 29(3)$ & $90 \pm 27(3)$ & $41 \pm 00(3)^{*}$ \\
Fiber size $\mu \mathrm{m}^{2}$ (insertion) & $138 \pm 41(3)$ & $151 \pm 47(3)$ & $37 \pm 8(3)^{*}$ \\
\hline
\end{tabular}

Values shown are mean \pm SD (number of animals is in parentheses). Fiber density (medial gastrocnemius) was estimated from a $400 \times 400 \mu \mathrm{m}^{2}$ area and fiber size (cross-section area) from 50 fibers per group. *Significant difference from wild type $(p<0.05, t$ test).

increase in myelinated sensory axons was already evident, although sensory myelination was not fully complete at this time. The early myelinating supernumerary sensory axons were likely from proprioceptive neurons because myelination of the excess axons in the cutaneous saphenous nerve was not apparent until P14 and not significantly different from controls until P21 (Fig. 7F). As expected, protracted myelination was also observed peripherally in the mixed quadriceps nerve of Bax KO mice (Fig. 7E).

Additional evidence that the increased small diameter axons may be derived from $\gamma$-MNs is their immunoreactivity for $\alpha 3 \mathrm{NKA}$, which is reported to be preferentially expressed in $\gamma-v s$ $\alpha$-MN axons (Dobretsov et al., 2003). The $\alpha 3$ NKA is selectively expressed in neurons (vs glia) and maintains the $\mathrm{Na}^{+} / \mathrm{K}^{+}$ionic gradient of the membrane potential. In rat ventral roots, strong immunolabeling for $\alpha 3 \mathrm{NKA}$ is only observed in small caliber $(<3 \mu \mathrm{m})$ myelinated axons comprising $30 \%$ of total VR axons, a number consistent with previous estimates of $\gamma$-MN axons in 
A

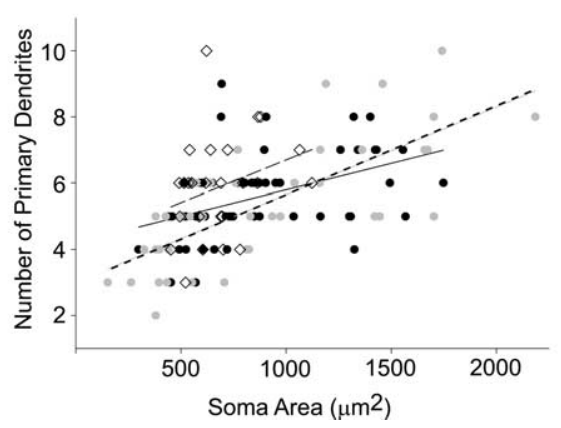

Figure 4. Analysis of dendritic morphology in WT, Bax KO, and MyoGDNF mice. A, Relationship between lumbar MN soma size and number of primary dendrites. WT (black circles; solid line; correlation coefficient, $r=0.44$ ), Bax K0 (gray circles; dotted line; $r=0.73$ ), and MyoGDNF (open diamonds; dashed black line; $r=0.29$ ) are shown. $\boldsymbol{B}$, Dendrite density in the lumbar ventral horn (arbitrary pixel values normalized to WT $=1$; mean \pm coefficient of variation). * Significant difference ( $p<0.05, t$ test) from wild-type. Values in parentheses are numbers of animals. The background mouse strain was an outbred CBA $\times$ C57BL6/J line.

mas. However, the smaller $\gamma$-MN size cells had fewer synapses per unit cell surface than the larger $\alpha$-MN size cells $(2.0 \pm 0.7$ vs $3.8 \pm 0.4 ; n=3 ; p=0.0008)$ regardless of genotype (WT or Bax KO). The small atrophied neonatal MNs observed by Sun et al. (2003) also exhibit normal-appearing cytoplasmic organelles and synapses, and except for their reduced size and scant cytoplasm, were otherwise indistinguishable from the larger MNs in neonatal Bax $\mathrm{KO}$ mice. The ultrastructure of large $\alpha$-MNs was also indistinguishable (Fig. $8 A, C$ ) between WT and Bax KO. Together, these data suggest that the small-diameter supernumerary L4 ventral root myelinated axons may represent phenotypically transformed $\alpha$ to $\gamma$-MNs, which innervate an expanded population of muscle spindles

adult rat and mouse ventral roots based on axon size alone (Whitehead et al., 2005). Additionally, $\alpha 3$ NKA-labeled axons are detected in polar regions of muscle spindles where $\gamma$-MNs terminate, but not in association with extrafusal muscles (Dobretsov et al., 2003). Although the cytology of ventral root axons was not as well preserved in the paraffin-embedded tissue that is required for $\alpha 3$ NKA immunolabeling, as it is in $1-\mu \mathrm{m}$-thick plastic sections, it was nonetheless clear, based on adjacent sections immunolabeled with a NF-H antibody, that the small diameter labeled structures are myelinated axons (Fig. 7G-I) (data not shown), and that there were more of these (2.8 times more labeled profiles) in the Bax KO $(174.2 \pm 8.9 ; n=5)$ than in the WT $(62.5 \pm$ $6.9 ; n=4 ; p<0.01, t$ test $)$. In contrast, there were no immunoreactive axons in the buccal branch of the facial nerve of either Bax KO or WT mice (data not shown), consistent with previous reports showing that the facial motor nucleus contains no $\gamma$-MNs and that facial muscles lack muscle spindles (Jin et al., 2004; Whitehead et al., 2005). In contrast to their axons, MN cell bodies in the spinal cord were not differentially labeled by anti- $\alpha 3$ NKA (data not shown).

To further determine whether the increased numbers of small myelinated $\mathrm{MN}$ axons in Bax KO mice represent $\gamma$-MNs, or also included the axons of markedly atrophic denervated $\alpha$-MNs, as suggested by Sun et al. (2003), we examined MNs by electron microscopy (Fig. 8). The atrophic MNs described by Sun et al. (2003) failed to myelinate and had a greatly smaller soma size with reduced cytoplasm. The ultrastructure of the small $\gamma$-sized MNs in the Bax KO was indistinguishable from WT MNs (Fig. $8 B, D)$, but appeared to differ from the apparent atrophied neonatal MNs with scant cytoplasm described by Sun et al. (2003). However, this difference may be more apparent than real because the atrophied MNs observed by Sun et al. (2003) were from neonatal mice, whereas the putative $\gamma$-MNs observed here are from adult mice. The differences in the amount of cytoplasm between the two likely reflects growth between the two ages (Fig. 3B) because the severely atrophied MN somas with scant cytoplasm noted by Sun et al. (2003) were never observed in the adult Bax KO. The cytoplasm of the $\gamma$-sized MNs had abundant mitochondria and endoplasmic reticulum, and axosomatic synaptic density appeared unchanged from WT: Bax KO, $2.9 \pm 0.5(n=3)$ versus BaxWT, $3.1 \pm 0.8$ synapses $(n=3)$ per $10 \mu \mathrm{m}$ of the MN soma surface perimeter. This similarity in synapse number between WT and Bax KO was observed for all MNs with either large $\left(>400 \mu \mathrm{m}^{2}\right)($ Fig. $8 A, C)$ or small $\left(<400 \mu \mathrm{m}^{2}\right)($ Fig. $8 B, D)$ so- in the hindlimbs that have been induced by the excess proprioceptive sensory neurons rescued from PCD by Bax deletion (Sun et al., 2003).

The buccal branch of the facial nerve that provides efferent innervation of whisker pad muscles is composed solely of $\alpha$-MNs (Dorfl, 1985; Semba and Egger, 1986; Whitehead et al., 2005). Increased numbers of small- to medium-sized myelinated axons were observed in the buccal branch of the Bax KO (Table 1, Fig. 1) and, as noted above, retrograde labeling of the whisker pads revealed significantly more labeled facial MNs $(30 \% ; p<0.01)$ in the Bax KO vs WT mice. Because the facial nucleus is devoid of $\gamma$-MNs, these data indicate that many Bax KO-rescued $\alpha$-MNs have the potential to myelinate and innervate their normal extrafusal muscle fiber targets. In contrast, as described in the following section, many of the excess $\alpha$-MNs in the spinal cord fail to innervate their muscle targets.

\section{A motoneuron population with unmyelinated axons in the Bax KO}

In a previous examination of Bax KO MNs, Sun et al. (2003) argued that the majority of the rescued population of Bax KO MNs failed to develop properly, their fate being retraction from muscle targets (denervation) and cellular atrophy. Although the present findings show an approximate tripling of the putative $\gamma$-MN population (if $<5 \mu \mathrm{m}$ axon diameter is used to discriminate $\alpha$-vs $\gamma$-MNs), there still remains a large population of abnormal unmyelinated ventral root axons (Fig. 9A) presumed to represent the atrophied MNs described previously (Sun et al., 2003). Large numbers of unmyelinated axons were present in the adult Bax KO ventral roots (Fig. 9A), but because of the large size of adult ventral roots and the high magnification level required to reliably visualize them (at least $8000 \times$ ) it was difficult to accurately quantify them. However, at P0 WT L4 ventral roots contained $1150 \pm 74$ unmyelinated axons, similar to the $1082 \pm 48$ myelinated ventral root axons present in the adult (compare Tables 1,5$)$ versus a total of $3427 \pm 560(n=3)$ in the P0 Bax KO, compared with the $1847 \pm 204$ myelinated axons present in the adult Bax KO (Table 1). Therefore assuming that all unmyelinated $\mathrm{P} 0$ axons remain in the adult Bax KO, then $\sim 1600$ unmyelinated axons, or $\sim 46 \%$ of the originally generated MN population, are present in the L4 ventral root. Increased numbers of unmyelinated axons were also found in mixed peripheral nerves of the Bax KO (Fig. 9B). However, because unmyelinated axons of sensory and autonomic origin are also normally present in WT 
mixed nerves, it was not possible to definitively determine the extent to which these represented atrophied $\alpha$-MNs (Song et al., 1999). The unmyelinated VR axons were observed both as individual axons and in small and large clusters (Remak-like bundles). Peripheral nerves examined at $\mathrm{P} 0$ in the Bax KO, before myelination, also had increased numbers of very small axons (Table 5). The total increase in axon number in the adult was larger than could be accounted for by myelinated axons alone, consistent with the failure of many $\alpha$-MN axons to myelinate in the Bax KO. At premyelination stages, axon diameter was significantly reduced in the $\operatorname{Bax} \mathrm{KO}$ (e.g., phrenic nerve $11 \%$, buccal nerve $18 \%$ ) with the typical unimodal distribution being shifted to smaller size classes. Together, these data indicate that the adult Bax KO contains an abnormal population of small unmyelinated L4 ventral root axons that project into peripheral nerves but do not innervate muscle targets and, thus, are nonfunctional because electrical stimulus strengths that would activate this abnormal, small-sized $\alpha$-MN population failed to facilitate muscle activation (Table 4 ).

In examining the ultrastructure of $\mathrm{P} 0$ Bax KO ventral roots it became apparent that a portion of the supernumerary axon population consisted of exceedingly small, abnormally bundled unmyelinated axons (Fig. 9D,E), consistent with the atrophy of MN somas (Fig. 3C). It was suggested previously (Sun et al., 2003) that the abnormal axons belong to trophic factordeprived MNs that, unable to undergo PCD, had lost target contacts, atrophied, and failed to be myelinated or integrated into the neuromuscular system. We reasoned that if these putative $\alpha$-MNs did indeed have insufficient trophic support, further reduction of trophic signaling would accentuate this phenotype. To test this hypothesis, GDNF signaling was inhibited by eliminating the expression of GFR $\alpha 1$ in GFR $\alpha 1$ KO mice (Enomoto et al., 1998). In the GFR $\alpha 1 \mathrm{KO}$ mouse, MN survival was reduced by $27 \%(811 \pm 75$, $n=4$ vs $1150 \pm 74, n=4, \mathrm{WT} ; p<0.01, t$ test) based on L4 ventral root axon counts, a value similar to previous reports (Sanchez et al., 1996; Cacalano et al., 1998; Oppenheim et al., 2000). However, because Bax KO MNs are unable to undergo PCD when trophic support is reduced (Deckwerth et al., 1996; White et al., 1998), the small unmyelinated axon phenotype should be enhanced in double GFR $\alpha 1 /$ Bax KO mice. As predicted, ventral roots from GFR $\alpha 1 / B a x$ double $\mathrm{KO}$

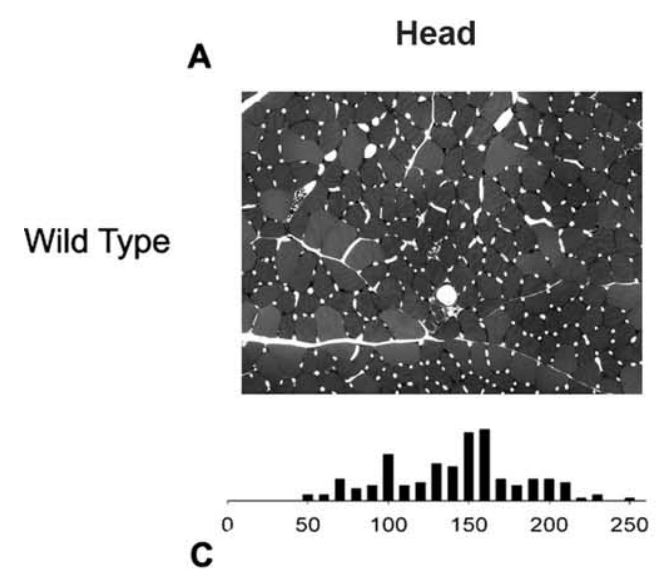

B Insertion

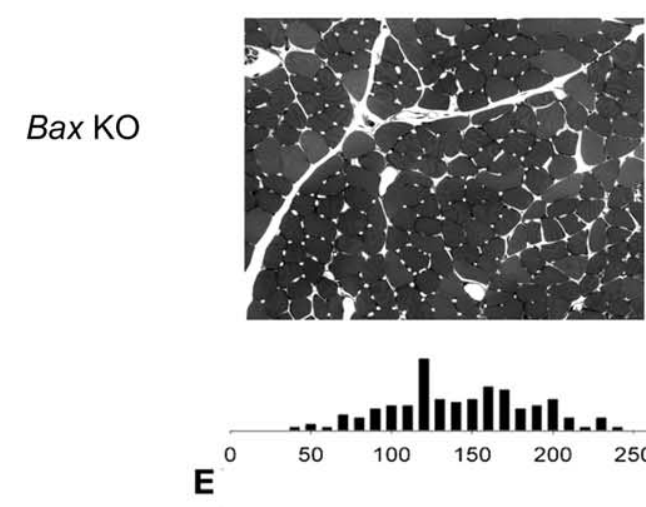

D
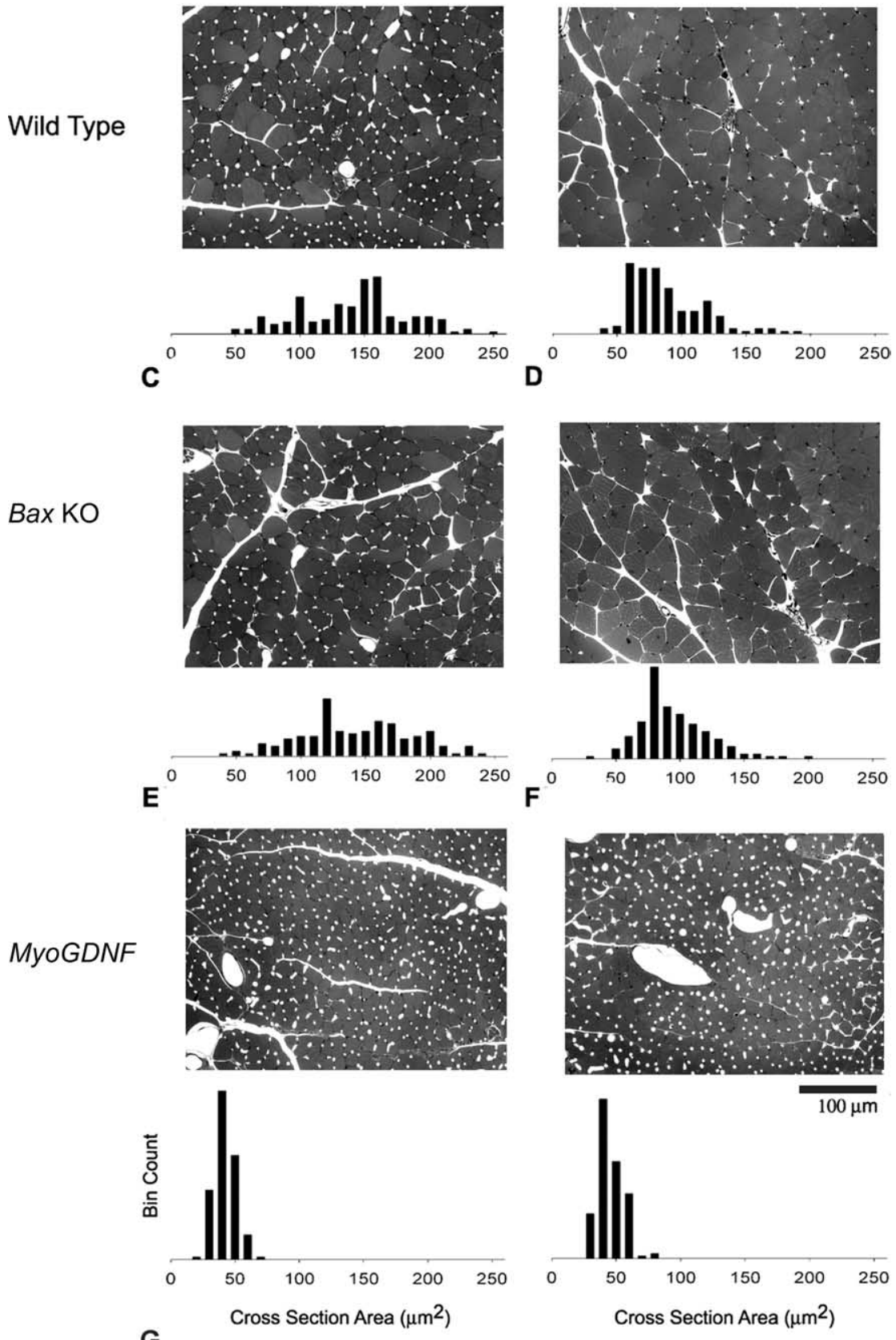

G

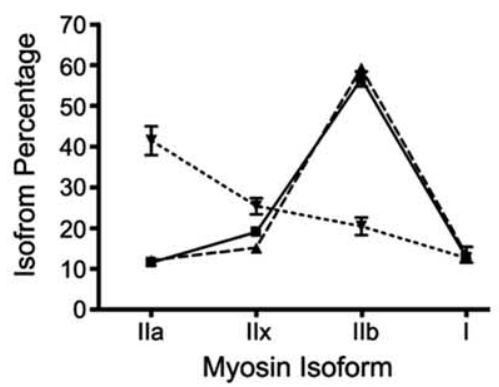

Figure 5. $A-F$, Montages of cross sections of the medial gastrocnemius muscle at the head region $(A, C, E)$, where a mixed fiber population resides in WT, and the insertion region $(\boldsymbol{B}, \boldsymbol{D}, \boldsymbol{F})$, where a homogenous large fiber population resides in WT mice. Wild-type $(\boldsymbol{A}, \boldsymbol{B}), \operatorname{Bax} \mathrm{KO}(\boldsymbol{C}, \boldsymbol{D})$ and MyoGDNF $(\boldsymbol{E}, \boldsymbol{F})$ mice (1 month old) are shown. Note the increased capillaries in $\boldsymbol{E}$ and $\boldsymbol{F}$. Histograms show muscle fiber cross-section area measurements ( $n=3$ animals, 50 myofibers per animal). $\boldsymbol{G}$, The proportion of myosin heavy chain isoforms in the medial gastrocnemius of adult WT (solid line), Bax KO (dashed line), and MyoGDNF (dotted line) mice as determined by SDS-PAGE (see Materials and Methods). Error bars indicate SD. 


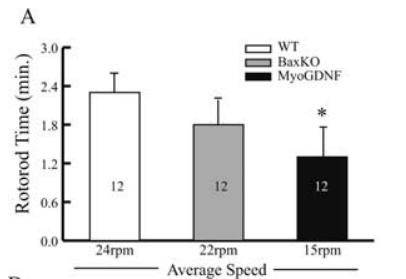

B
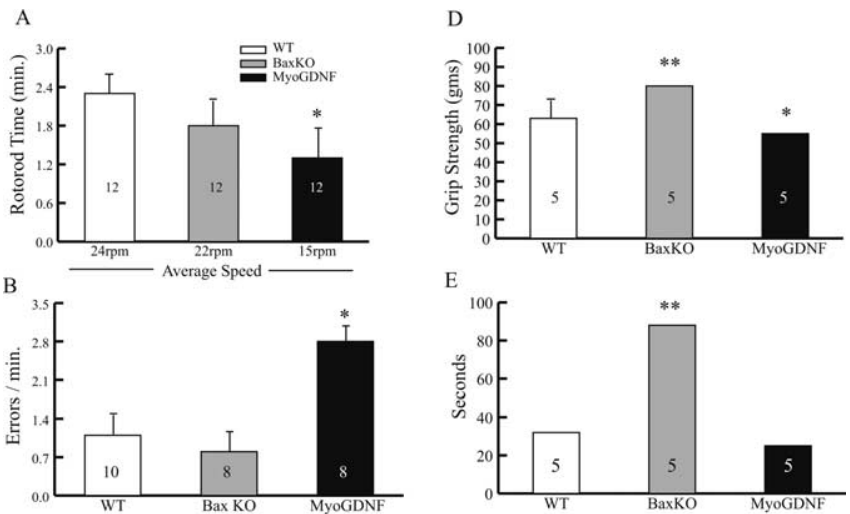

E
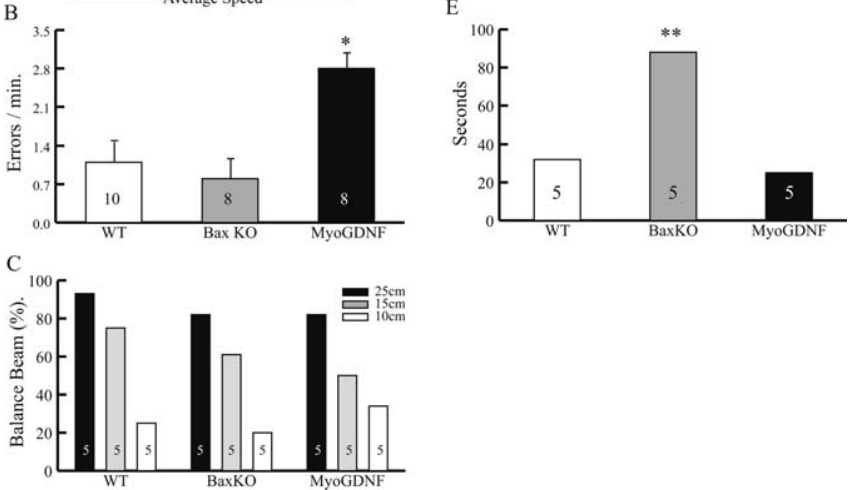

Figure 6. Behavioral tests of adult WT, Bax KO, and MyoGDNF mice. $\boldsymbol{A}$, The duration and speed attained (mean \pm SD) before falling off the rotorod. ${ }^{*} p<0.005$ versus WT control $(t$ test). $\boldsymbol{B}$, The number (mean \pm SD) of errors (see Materials and Methods) per minute in the hole board test. ${ }^{*} p<0.0005$ versus WT control ( $t$ test). $\boldsymbol{C}$, The proportion (percentage) of animals that successfully crossed the different size balance beams in a 2 min test. $D$, Grip strength in grams of force (mean \pm SD). ${ }^{*} p<0.01,{ }^{* *} p<0.005$ versus WT control ( $t$ tests). $\boldsymbol{E}$, Duration in seconds (mean \pm SD) before falling from the hanging wire. ${ }^{* *} p<0.002$ versus WT control ( $t$ test).

mice had a significantly enlarged population of abnormal bundled unmyelinated axons compared with the Bax KO mouse (Fig. $9 \mathrm{C}-\mathrm{H})$ (data not shown). These data are consistent with the suggestion that the unmyelinated axons in the ventral roots of Bax $\mathrm{KO}$ mice represent a population of atrophied $\alpha$-MNs rescued from PCD that fail to innervate muscle targets and therefore are deprived of trophic support required for sustaining cell size and axon myelination (Sun et al., 2003). Because the cell bodies of these atrophied $\alpha$-MNs were included in the population of small MNs $\left(<400 \mu \mathrm{m}^{2}\right)$ examined for MN ultrastructure and the quantification of axosomatic synapses (Fig. 8), despite their atrophied and unmyelinated phenotype, they appear to have otherwise differentiated normally. Additionally, we and others have shown previously that developing and mature, large and small MNs in Bax KO and MyoGDNF mice express a number of MNspecific markers, including the GDNF receptors c-ret and GFR $\alpha 1$ (Sun et al., 2003), acetylcholinesterase (Kinugasa et al., 2002), choline acetyltransferase, the vesicular acetylcholine transporter, and the transcription factors HB-9 and islet 1/2 (R. W. Oppenheim, T. Gould, A. Winseck, unpublished observation). Accordingly, even the atrophic, unmyelinated MNs in the Bax KO express a typical MN phenotype that includes the ability to regrow axons after neonatal axotomy (Sun and Oppenheim, 2003).

\section{The fate of supernumerary motoneurons in MyoGDNF mice} In striking contrast to the Bax KO, in MyoGDNF mice the number of L4 ventral root myelinated axons was increased in both the small $\alpha$ - and $\gamma$-MN size populations and there were striking phenotypic changes in the muscle targets of these mice. However, unlike the Bax KO, the number of muscle spindles was unchanged in MyoGDNF medial gastrocnemius muscles $(9.7 \pm 1.2$, $n=3$ vs $9.0 \pm 0.0, n=3$ ), in agreement with unaltered numbers of myelinated sensory axons in the L4 DR. In adult MyoGDNF animals, muscles appeared redder in color, had increased capillaries, and individual muscles were smaller and histologically distinct from WT (Fig. 5, Table 4). The smaller size was not attributable to atrophy, but rather to a change in fiber type (Fig. 5). Most mammalian muscles, including the medial gastrocnemius, consist of three muscle fiber types (Floeter, 1999): slow (type I), fast fatigue-resistant (type IIa), and fast-fatigable (type IIxb). MyoGDNF mice exhibit a marked increase in type IIa myofibers. A higher density of fibers was present but fibers had smaller diameters (Table 4) that were distributed throughout the muscle, including near the ankle tendon, which is composed exclusively of large-diameter fibers in WT muscle (Fig. $5 E, F$ ). Myosin heavy chain composition (Fig. 5) and neuromuscular activation (Table 4) were also altered. Acid and alkaline stable myosin ATPase histochemistry (Guth and Samaha, 1970) was consistent with the muscle phenotype transformation to an increase of type IIa in MyoGDNF mice (data not shown).

The gastrocnemius muscle in MyoGDNF mice did not produce as much force (twitch force and tetanus force) as WT and Bax KO animals, possibly because MyoGDNF mice have less muscle mass and smaller fiber size (Table 4). However, the gastrocnemius muscle in $M y o G D N F$ mice was more resistant to fatigue (indicated as tetanus 50\% fatigue) (Table 4), possibly because it has higher numbers of type IIa (fatigue-resistant) and lower numbers of type IIb fibers (fast-fatigable) (Fig. 5). The greater capillary density (Fig. 5) is consistent with a higher number of type IIa fatigue-resistant fibers in MyoGDNF animals. All three groups of mice have a similar proportion of type I fibers (small fibers and slow contraction), although there are striking differences in twitch force, tetanus force, and fatigue-resistance among them (Table 4).

The few MyoGDNF mice that survived to adults (there was very high neonatal and juvenile mortality and reduced body growth) exhibited abnormal hindlimb posture (perhaps because of the reduced muscle mass), and their behavioral performance was significantly impaired on some (rotorod, hole board, grip strength, hanging wire), but not all (balance beam) tests of motor behavior (Fig. 6). Estimates of numbers of neuromuscular junctions in MyoGDNF mice appeared slightly lower (Table 4), but this difference was not statistically significant.

The relationship between primary dendrite number and $\mathrm{MN}$ soma size was maintained in MyoGDNF mice, although Golgistained MNs in the largest $\alpha$-MN size class were absent (Tables 2, $3)$. The overall density of Golgi-stained dendrites within the ventral horn was increased in MyoGDNF mice (Fig. 4B).

The time course of ventral root and quadriceps nerve myelination in postnatal MyoGDNF mice was not as protracted as it was in the Bax $\mathrm{KO}$ (Fig. 7C,E) and no difference was observed in the myelination of sensory axons (dorsal root and saphenous nerve) (Fig. $7 D, F)$. However, similar to the Bax KO, a large increase in $\alpha 3$ NKA-immunolabeled axons was observed in the L4 ventral root (Fig. 7I) (data not shown). The phenotype of these excess labeled MN axons may be either $\gamma$-MNs or the often overlooked $\beta$-MN population (Burke, 1981; Matthews, 1981; Vult von Steyem et al., 1999) in which individual MN axons branch and innervate both extrafusal and intrafusal (muscle spindles) muscles. It has been estimated that one-third of mammalian muscle spindles are innervated by $\beta$-MNs (Emonet-Denand et al., 1992; Floeter, 1999). The increase in smaller-sized MNs having the anatomical characteristics of fast twitch, fatigue-resistant MNs (Burke, 1981), together with the altered MyoGDNF muscle phenotype that resembles type IIA/fast twitch, fatigue-resistant, oxidative, glycolytic muscle, is what might be expected if these represent a population of $\beta$-like MNs. However, we have no ev- 
idence indicating whether or not any of the $\alpha 3$ NKA-immunolabeled axons coinnervate intrafusal and extrafusal muscle fibers (but see Dobretsov et al., 2003).

\section{Can GDNF rescue Bax $\mathrm{KO}$ motoneurons from atrophy?}

In a previous report on Bax KO MNs (Sun et al., 2003), it was suggested that the atrophied unmyelinated population of $\alpha$-MNs might develop normally if provided with sufficient trophic support. In fact, they observed that daily GDNF treatment of Bax KO mice from P1-P14 induced a significant increase in the soma size of spinal and facial MNs. If correct, then the prediction is that in the presence of sufficient trophic factors, the unmyelinated atrophic $\alpha$-MNs should also increase in size, myelinate, and contribute to increased numbers of myelinated axons in ventral roots and peripheral nerves. To test this, we treated Bax KO mice with GDNF at doses (daily intraperitoneal injection from $\mathrm{P} 1-\mathrm{P} 14$ at $1 \mu \mathrm{g} / \mathrm{g}$ or from P11-P21 with 10 $\mu \mathrm{g} / \mathrm{g}$ ) in excess of those used previously to significantly modify postnatal and adult neuromuscular development (Keller-Peck et al., 2001; Hoke et al., 2003; Sun et al., 2003). Surprisingly, we observed only a modest increase in the number of myelinated motor axons in ventral roots or peripheral nerves (Table 6). Although the GDNF injections may have accelerated the rate of myelination (Hoke et al., 2003), total numbers never significantly exceeded adult values and in no case was the absolute change $>13 \%$ (L4 ventral root at P21), whereas complete myelination of the atrophic population after GDNF treatment would have led to an almost fivefold increase.

It remained possible, however, that postnatal injection of GDNF was too late in the developmental process to significantly alter the unmyelinated phenotype (Keller-Peck et al., 2001). To test this possibility, Bax KO mice were crossed with MyoGDNF mice, which greatly overexpress GDNF in muscle from embryonic stages (Nguyen et al., 1998; Whitehead et al., 2005). Because of the low survival of neonatal and juvenile MyoGDNF and MyoGDNF/Bax KO double mutants, it was not possible to examine these mice at later developmental stages (only two MyoGDNF/ Bax KO double mutant mice survived to P10). On P0, however, MyoGDNF/Bax KO double-mutant mice had MN soma sizes intermediate to those of Bax $\mathrm{KO}$ and MyoGDNF mice and the apparent atrophy of the small-sized population observed in Bax KO mice was not observed (Fig. 3C). However, the atrophic ventral root axon phenotype observed at P0 in Bax KO persisted in the double mutants (data not shown). Because a complete reversal of the atrophic MN phenotype was not observed, the MN phenotype of double Bax KO/MyoGDNF mice appeared intermediate to that of Bax KO and MyoGDNF mice.

\section{Discussion}

Bax KO mice

Several previous studies reported a complete rescue of spinal and cranial MNs, and sensory neurons in the DRG, from develop-
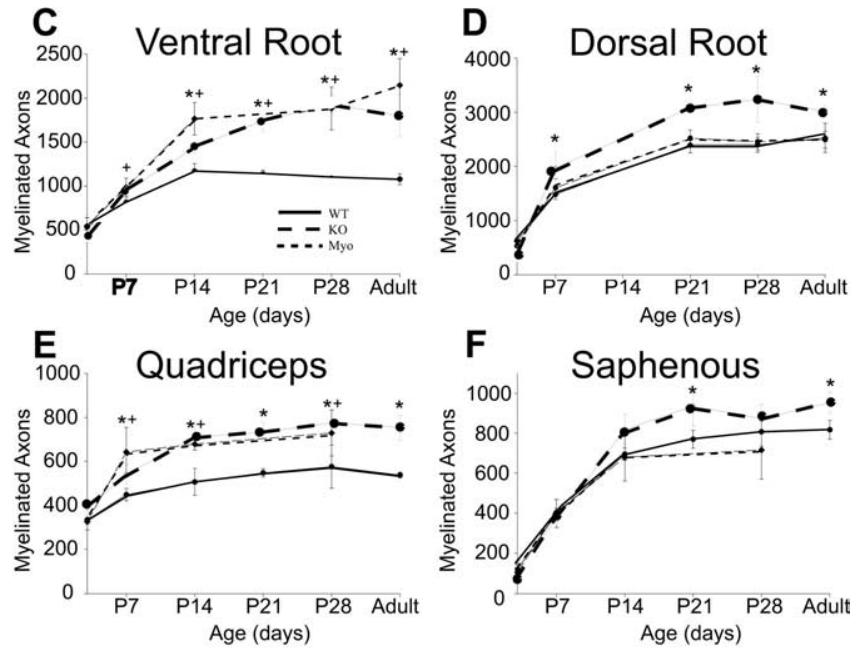

H $\quad \mathrm{Bax} \mathrm{KO}$

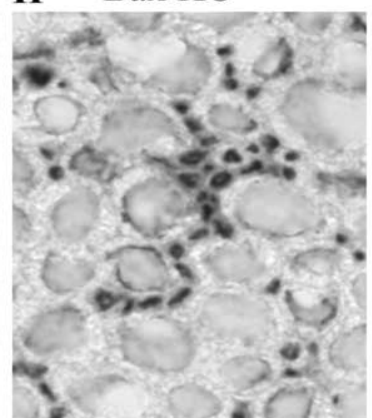

I MyoGDNF

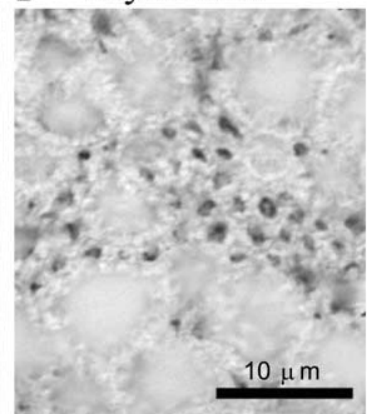

Figure 7. Based on size and immunolabeling, the supernumerary myelinated MNs in Bax KO mice are $\gamma$-like MNs, whereas

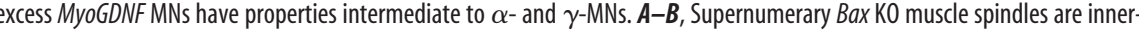
vated and indistinguishable from WT. *Intrafusal myofibers; arrows, axons. $\mathbf{C}-\boldsymbol{F}$, Developmental time course of myelination. WT black line), Bax KO (dashed black line), and MyoGDNF (dotted black line) are shown. *Bax KO and ${ }^{+}$MyoGDNF are significantly different from WT ( $p<0.05, t$ test). Values shown are mean \pm SD. G-I, A putative $\gamma$-MN marker (antibody to $\alpha 3$ subunit of the $\mathrm{Na}^{+} / \mathrm{K}^{+}$ATPase) primarily labels small-diameter myelinated axons in the L4 VR.

mental PCD in Bax KO mice (Deckwerth et al., 1996; White et al., 1998; Patel et al., 2003; Sun et al., 2003; Jacob et al., 2005). The rescued cells persist in adult animals, develop a neuronal phenotype, and project axons into peripheral nerves. However, whether the presence of tens of thousands of excess neurons perturbs physiology, behavior, or other aspects of the neuromuscular system (e.g., muscle differentiation) has received very little attention (Buss et al., 2006).

Although we have observed a number of significant changes in the neuromuscular system of Bax KO mice, the extent to which several other aspects of neuromuscular development are relatively normal is particularly striking. These are summarized in Table 7. In keeping with the complete rescue of MNs from PCD, there are increased numbers of axons in VRs and peripheral nerves and an increase in retrogradely labeled MNs (facial) after tracer injections into target regions. However, there is an overall reduction in the size of $\mathrm{MN}$ cell bodies and axons, including a striking increase in small MNs with myelinated axons in the size range of $\gamma$ - vs $\alpha$-MNs (i.e., $\mathrm{MN}$ somas $<400 \mu \mathrm{m}^{2}$ and axons $<4-5 \mu \mathrm{m})$. Bax $\mathrm{KO}$ mice also had a large population of MNs with small unmyelinated axons $(<4 \mu \mathrm{m})$ that are not present in WT animals. Based on axon counts in VRs and peripheral nerves, virtually all rescued MNs appear to project axons in close proximity to muscle targets. Coincident with increased numbers of myelinated $\gamma$-size MNs, there were increased numbers of muscle spindles and increased numbers of VR axons immunolabeled for 

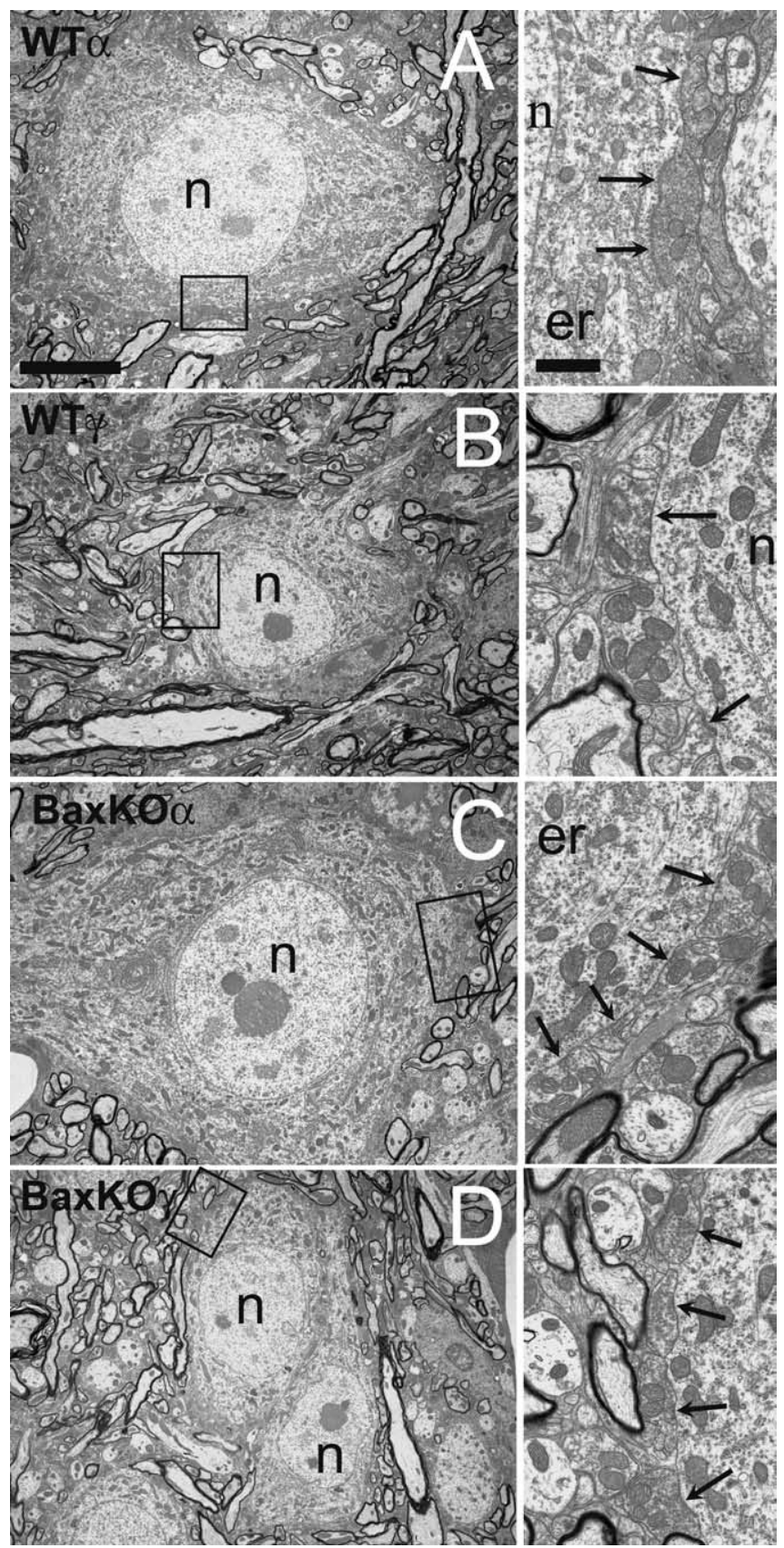

Figure 8. Ultrastructure of WT and Bax KO $\alpha$-and $\gamma$-sized MNs (soma area $>400 \mu \mathrm{m}^{2}$ and $<400 \mu \mathrm{m}^{2}$, respectively). Low-magnification electron micrographs show relative difference in size between $\alpha(\boldsymbol{A}, \boldsymbol{C})$ and $\gamma(\boldsymbol{B}, \boldsymbol{C})$ MNs. No significant differences in synapse density were found between WT and Bax KO $\alpha$-or $\gamma$-MNs, although $\gamma$-MNs had fewer synapses per unit cell surface than larger $\alpha$-MNs. Boxed areas are enlarged at right to show synapse morphology; arrows point to synaptic densities with vesicles apparent on the postsynaptic elements. $n$ Nucleus; er, endoplasmic reticulum. Scale bars: (in $\boldsymbol{A}$, left) $\boldsymbol{A}-\boldsymbol{D}$, left, $10 \mu \mathrm{m}$; (in $\boldsymbol{A}$, right) $\boldsymbol{A}-\boldsymbol{D}$, right, $1 \mu \mathrm{m}$.

$\alpha 3 \mathrm{NKA}$, a putative marker for peripheral axons of $\gamma$-MNs (Dobretsov et al., 2003).

In the absence of reliable phenotypic markers for identifying $\alpha$-versus $\gamma$-MNs in the spinal cord, very little is known about the mechanisms by which these two motoneuron cell types diverge during development. The differences in soma and axon size that have been used previously to distinguish between them is somewhat imprecise and in any case can only be used in older postnatal mammals after myelination and long after each cell type has se- lectively innervated intrafusal ( $\gamma$-MNs) and extrafusal ( $\alpha$-MNs) muscle fibers (Milburn, 1973; Kozeka and Ontell, 1981; McHanwell and Biscoe, 1981; Tourtellotte et al., 2001).

Recordings of the muscle force generated by electrical stimulation of the sciatic nerve revealed little, if any, difference between WT and Bax KO mice, consistent with the normal phenotype of Bax KO extrafusal muscle fibers and the normal (WT) number of NMJs in Bax KO muscle.

Despite our failure to observe increased numbers of NMJs, changes in muscle force production, or altered muscle size, Bax $\mathrm{KO}$ mice exhibited increased performance on two behavioral tests used to assess muscle strength (grip strength and the hanging wire test). These changes may reflect the increased number of innervated muscle spindles in the Bax KO or, alternatively, the combined rescue of sensory neurons, spinal interneurons, and MNs, together with increased numbers of innervated muscle spindles in the Bax KO (Sun et al., 2003), may alter motor behavior by modifying the function of sensorimotor pathways in the CNS (Floeter, 1999). Electrophysiological studies are in progress to examine the function of spinal cord circuits in Bax $\mathrm{KO}$ mice.

\section{MyoGDNF mice}

As summarized in Table 7, MyoGDNF mice exhibit a number of similarities to and differences from the Bax KO. Some of the differences observed may stem from the lack of a complete rescue of MNs in MyoGDNF mice, consistent with the recent report that GDNF may be mainly required for the survival of mouse $\gamma$-MNs (Whitehead et al., 2005). Despite the increase in putative $\gamma$-MNs in MyoGDNF mice, muscle spindle numbers were similar to control values. This difference between Bax KO and MyoGDNF mice is likely attributable to the failure of GDNF to rescue proprioceptive sensory neurons from PCD (Oppenheim et al., 2000), resulting in the lack of supernumerary spindle induction.

Together, the data presented here and in the report by Whitehead et al. (2005) are consistent with GDNF being a survival factor for $\gamma$-MNs. However, we also find that MyoGDNF mice exhibit a striking and previously undetected alteration in muscle fiber phenotype involving a significant increase in type IIa fasttwitch myofibers. This raises the interesting question of whether the increase in putative $\gamma$-MNs (or both $\gamma$ - and small $\alpha$-MNs) is a result of GDNF acting directly on MNs versus its effect on muscle that then indirectly alters $\mathrm{MN}$ phenotype or selectively promotes $\gamma$-MN survival. Muscle-derived GDNF acting directly on MNs may, in fact, be the driving force in altering muscle phenotype (Vogel and Landmesser, 1987; Nemeth, 1990; Jacobson, 1991).

Neuromuscular physiology in MyoGDNF mice differed from both Bax KO and WT mice with muscles producing less force and being more resistant to fatigue. These differences are consistent with the striking modification of muscle fiber phenotype in MyoGDNF mice, including less muscle mass, small fiber size, and more fatigue-resistant (type IIa) muscle fibers.

With the exception of the balance beam test, MyoGDNF mice performed more poorly on all of the other behavioral tests, including the rotorod, hole board, grip strength, and the hanging wire. Although these deficits may be related to the marked change in muscle phenotype, they may also be related to genetic background $(\mathrm{C} 57 \mathrm{BL} / 6 \mathrm{~J} \times \mathrm{CF} 1)$ or the reduced body weight and persistence of polyneuronal innervation (Nguyen et al., 1998; KellerPeck et al., 2001); electrophysiological studies of neuromuscular function that are presently underway will be required to more completely assess the basis for the striking behavioral phenotype in MyoGDNF mice. 


\section{GDNF and MN development in Bax KO mice}

In a previous study examining neuromuscular development in Bax KO mice, we suggested that the small $\alpha$-MNs with unmyelinated axons represented Bax KOrescued $\mathrm{MNs}$ that failed to differentiate normally because of a failure to obtain sufficient muscle-derived trophic support (e.g., GDNF). Accordingly, we found that postnatal treatment with exogenous GDNF increased the soma size of spinal and facial MNs in the Bax KO (Sun et al., 2003).

We have now extended our examination of the effects of GDNF in Bax KO mice using three different approaches. (1) We asked whether the elimination of GDNF signaling increased the unmyelinated MN phenotype in Bax/GFR $\alpha 1$ double KO mice compared with the Bax KO. As predicted, double-mutant mice exhibited a significant increase in unmyelinated VR axons. (2) We reasoned that if the presence of small, unmyelinated axons is attributable to insufficient trophic support, then providing excess GDNF postnatally may result in an increase in the number of myelinated axons. GDNF may regulate myelination by stimulating axons to express neuregulin-1, whose expression levels on axons regulates myelination (Hoke et al., 2003; Nave and Salzer, 2006). Although there was a modest increase in the number of myelinated axons in the L4 VR on P21, the increase did not exceed adult values. Because it remained possible that postnatal GDNF treatment was too late to substantially affect axon size or myelination, we turned to a final strategy: (3) Bax KO mice were crossed with MyoGDNF mice in which increased muscle expression of GDNF begins embryonically (Nguyen et al., 1998). Unfortunately, because virtually all double-mutant animals died early postnatally, we were only able to examine animals at P0 before the onset of myelination in the VR. However, soma size measures done at $\mathrm{P} 0$ revealed a significant increase in the double mutants such that $\mathrm{MN}$ size was intermediate to that of Bax $\mathrm{KO}$ and MyoGDNF mice.

\section{Neuromuscular development after $\mathrm{MN}$ rescue by activity blockade}

Because the rescue of MNs by activity blockade results in perinatal lethality caused by respiratory failure at birth or hatching, most aspects of neuromuscular development could not be examined in paralytic chicken and mouse models. At early stages after the rescue of MNs in both chicken and mouse, $\mathrm{MN}$ size is similar to control, whereas later in development (chicken), as also seen in Bax KO and MyoGDNF mice, there was a reduction in soma size and in the size of myelinated axons. The rescue of MNs by activity blockade in the chicken has also been reported to alter musclefiber phenotype (Ding et al., 1983; Gauthier et al., 1984; Sohal and Sickler, 1986). Previous studies of MN development after their

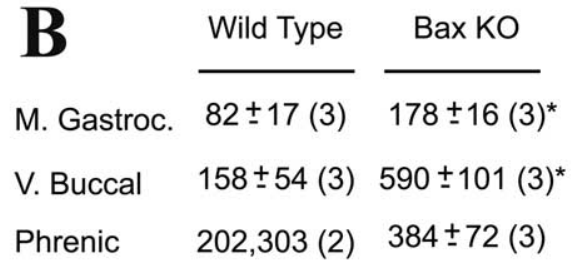

\section{D $\mathrm{Bax} \mathrm{KO}$}
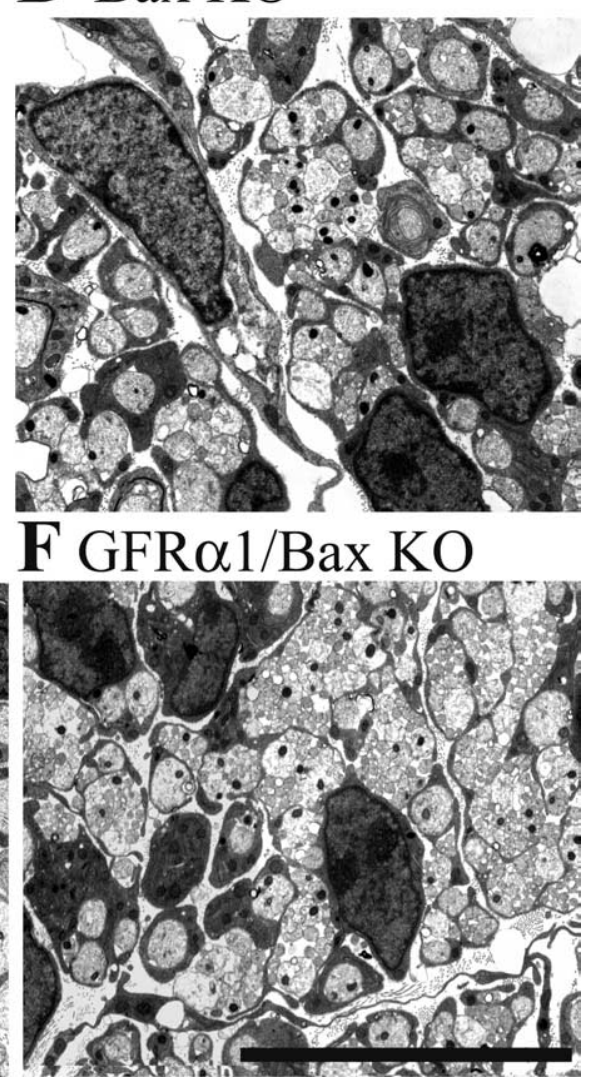

Figure 9. Motoneuron axons in the ventral roots and peripheral nerves. $\boldsymbol{A}$, Many unmyelinated axons (asterisks) $0 c c$ ur in the $L 4$ ventral root of adult Bax KO mice. $\boldsymbol{B}$, Increased numbers of unmyelinated axons in peripheral nerves of the adult $B a x$ KO. $\boldsymbol{C}-\boldsymbol{F}$, Ventral root axons in P0 WT $(\boldsymbol{C}), B a x$ KO $(\boldsymbol{D})$, GFR $\alpha 1$ KO $(\boldsymbol{E})$, and GFR $\alpha 1 / B a x$ double mutants $(\boldsymbol{F})$. Note the increase in smal unmyelinated axons in $\boldsymbol{F}$. Schwann cells (SC) are indicated $\boldsymbol{C}$. In $\boldsymbol{B}$, the asterisk indicates $p<0.05$ versus WT( $t$ tests) and the values are mean \pm SD. Scale bars: $\boldsymbol{A}, 10 \mu \mathrm{m}$; (in $\boldsymbol{F}) \boldsymbol{C}-\boldsymbol{F}, 10 \mu \mathrm{m}$.

Table 5. Numbers of unmyelinated axons and Dil labeled somas of PO wild-type and Bax KO mice

\begin{tabular}{lcc}
\hline & Wild type & Bax KO \\
\hline Phrenic n. (axons) & $285 \pm 16(5)$ & $502 \pm 84(5)^{*}$ \\
Phrenic n. (somas-Dil) & $323 \pm 33(5)$ & $434 \pm 66(4)^{*}$ \\
Buccal n. (axons) & $1622 \pm 215(3)$ & $3314 \pm 693(3)^{*}$ \\
L4 ventral root (axons) & $1150 \pm 74(4)$ & $3427 \pm 564(3)^{*}$ \\
\hline
\end{tabular}

Values shown are mean \pm SD (number of animals is in parentheses). ${ }^{*} p<0.01, t$ test. n., Nerve.

rescue by activity blockade in the chicken embryo have also found normal ultrastructure and dendritic development, control numbers of afferent synapses onto MNs, normal biochemical (cholinergic) differentiation, and normal posthatching motor behavior (Pittman and Oppenheim, 1979; Oppenheim and Chu-Wang, 1983; Oppenheim, 1984; Okada et al., 1989; Oppenheim et al., 1989). However, there is one aspect of neuromuscular development that is markedly different between animals (chicken and 
Table 6. The effect of GDNF on myelination of atrophic MNs

\begin{tabular}{lcccc}
\hline & Adult Bax K0 & P21 Bax K0 & P14 Bax K0 & P1-P14 GDNF \\
\hline L4 ventral root & $1847 \pm 204(n=11)$ & $1742 \pm 126(n=5)$ & $1440 \pm 66(n=5)$ & $711-P 21$ GDNF \\
Quadriceps & $764 \pm 58(n=10)$ & $732 \pm 43(n=4)$ & $710 \pm 56(n=6)$ & $774,737(n=2)$ \\
LGS & $271 \pm 12(n=11)$ & & $2011 \pm 80^{*}(n=4)$ \\
\hline
\end{tabular}

Values shown are mean \pm SD (number of animals is in parentheses). LGS, Lateral gastrocnemius-soleus. ${ }^{*} p<0.05, t$ test, P21 Bax K0 versus P21 Bax K0/GDNF.

Table 7. A summary of some of the major features examined in the neuromuscular system of Bax KO and MyoGDNF mice

\begin{tabular}{|c|c|c|}
\hline & Bax KO & MyoGDNF \\
\hline MN number & $\uparrow$ complete rescue & $\uparrow$ partial rescue \\
\hline \multicolumn{3}{|l|}{ Axon number } \\
\hline VR myl & $\uparrow$ & $\uparrow$ \\
\hline VR unmyl & $\uparrow$ & $=\mathrm{WT}$ \\
\hline MG & $\uparrow$ & $\uparrow$ \\
\hline Facial & $\uparrow$ & $=\mathrm{WT}$ \\
\hline MN soma size & $\downarrow$ & $\downarrow$ \\
\hline MN axon size & $\downarrow$ & $\downarrow$ \\
\hline Retrograde labeling & $\uparrow$ facial & n.d. \\
\hline NMJs & $=\mathrm{WT}$ & $=\mathrm{WT}$ \\
\hline \multicolumn{3}{|l|}{ Dendrites } \\
\hline Primary & $=\mathrm{WT}$ & $=\mathrm{WT}$ \\
\hline Density & $=\mathrm{WT}$ & $\uparrow$ \\
\hline MN synapses & $=\mathrm{WT}$ & n.d. \\
\hline MN ultrastructure & $=\mathrm{WT}$ & n.d. \\
\hline \multicolumn{3}{|l|}{ Muscle } \\
\hline Extrafusal & $=\mathrm{WT}$ & Altered (see text; Fig. 5) \\
\hline $\begin{array}{l}\text { Intrafusal (number of spin- } \\
\text { dles) }\end{array}$ & $\uparrow$ & $=\mathrm{WT}$ \\
\hline \multicolumn{3}{|l|}{ MN phenotype } \\
\hline ChAT & $=W T$ & $=\mathrm{WT}$ \\
\hline $\mathrm{AChE}$ & $=\mathrm{WT}$ & $=\mathrm{WT}$ \\
\hline VAchT & $=\mathrm{WT}$ & $=\mathrm{WT}$ \\
\hline HB9 & $=\mathrm{WT}$ & $=\mathrm{WT}$ \\
\hline Islet-1 & $=\mathrm{WT}$ & $=\mathrm{WT}$ \\
\hline c-Ret & $=\mathrm{WT}$ & $=W T$ \\
\hline GFR $\alpha 1$ & $=\mathrm{WT}$ & $=W T$ \\
\hline$\alpha 3$ NKA & $\uparrow$ & $\uparrow$ \\
\hline MN physiology & $=\mathrm{WT}$ & Altered (see text; Table 3) \\
\hline Behavior & Altered (see text; Fig. 6) & Altered (see text; Fig. 6) \\
\hline
\end{tabular}

${ }^{\uparrow}$ Increased relative to $\mathrm{WT}^{\downarrow}{ }^{\downarrow}$ decreased relative to $\mathrm{WT}$; unmyl, unmyelinated; myl, myelinated; MG, medial gastrocnemius; VAchT, vesicular acetylcholine transporter; n.d., not determined; = WT, similar to WT.

mammals) with excess MNs after activity blockade versus Bax $\mathrm{KO}$ and MyoGDNF mice. Neither MyoGDNF nor Bax KO mice exhibit the striking increases in intramuscular axon branching or in the number of synapses on individual extrafusal myofibers observed after activity blockade in chick and mouse embryos (Ding et al., 1983; Oppenheim and Chu-Wang, 1983; Oppenheim, 1984; Oppenheim et al., 1986; Hall et al., 1988; Landmesser, 1992; Tang and Landmesser, 1993; Misgeld et al., 2002; Brandon et al., 2003). This difference may be attributable to the MNs rescued by activity blockade having greater access to muscle-derived trophic support for promoting branching and synaptogenesis (Landmesser, 1992; Oppenheim et al., 2003).

In all of the models examined here, MNs rescued from PCD only completed their differentiation when there was an associated direct or indirect phenotypic change in target muscle. Excess myelinated Bax KO MNs likely innervated an expanded population of muscle spindles and the excess MNs in the MyoGDNF mouse and paralytic chick innervate a target with a strikingly changed muscle fiber phenotype. In contrast, in the absence of a change in the number or phenotype of extrafusal myofibers in the Bax KO, a large population of $\alpha$-MNs fail to grow normally or become myelinated and they lack synaptic contacts with muscle targets. With the possible exception of the ChAT KO mice, which die at birth before the completion of many aspects of neuromuscular development, in no case was a change in MN number observed without an associated change in either $\mathrm{MN}$ or muscle phenotype (extrafusal fiber type or muscle spindle quantity). Collectively, these data suggest that PCD may serve both quantitative and qualitative matching of MNs with their muscle targets (Hamburger and Oppenheim, 1982).

\section{References}

Brandon EP, Lin W, D'Amour KA, Pizzo DP, Dominguez B, Sugiura Y, Thode S, Ko CP, Thal LJ, Gage FH, Lee KF (2003) Aberrant patterning of neuromuscular synapses in choline acetyltransferase-deficient mice. J Neurosci 23:539-549.

Burke RE (1981) Motor units: anatomy, physiology, and functional organization. In: Handbook of physiology, Vol 2, The nervous system, motor control, pp 345-422. Bethesda: American Physiological Society.

Buss RR, Sun W, Oppenheim RW (2006) Adaptive roles of programmed cell death during nervous system development. Annual Rev Neurosci 29:1-35.

Cacalano G, Farinas I, Wang LC, Hagler K, Forgie A, Moore M, Armanini M, Phillips H, Ryan AM, Reichardt LF, Hynes M, Davies A, Rosenthal A (1998) GFR $\alpha 1$ is an essential receptor component for GDNF in the developing nervous system and kidney. Neuron 21:53-62.

Clarke PG, Oppenheim RW (1995) Neuron death in vertebrate development: in vivo methods. Methods Cell Biol 46:277-321.

Crawley JN (2000) What's wrong with my mouse? Behavioral phenotyping of transgenic and knockout mice. New York: Wiley.

Deckwerth TL, Elliott JL, Knudson CM, Johnson Jr EM, Snider WD, Korsmeyer SJ (1996) BAX is required for neuronal death after trophic factor deprivation and during development. Neuron 17:401-411.

Ding R, Jansen JK, Laing NG, Tonnesen H (1983) The innervation of skeletal muscles in chickens curarized during early development. J Neurocytol 12:887-919.

Dobretsov M, Hastings SL, Sims TJ, Stimers JR, Romanovsky D (2003) Stretch receptor-associated expression of alpha 3 isoform of the $\mathrm{Na}^{+}$, $\mathrm{K}^{+}$-ATPase in rat peripheral nervous system. Neuroscience 116 : $1069-1080$

Dorfl J (1985) The innervation of the mystacial region of the white mouse. A topographical study. J Anat 142:173-184.

Emonet-Denand F, Petit J, Laporte Y (1992) Comparison of skeletofusimotor innervation in cat peroneus brevis and peroneus tertius muscles. J Physiol (Lond) 458:519-525.

Enomoto H, Araki T, Jackman A, Heuckeroth RO, Snider WD, Johnson Jr EM, Milbrandt J (1998) GFR $\alpha 1$-deficient mice have deficits in the enteric nervous system and kidneys. Neuron 21:317-324.

Floeter MK (1999) Muscle, motor neurons and motor neuron pools. In: Fundamental neuroscience (Zigmond MJ, Bloom F, Landis SC, Roberts JL, Squire LR, eds), pp 863-887. New York: Academic.

Fraher JP, Kaar GF, Bristol DC, Rossiter JP (1988) Development of ventral spinal motoneurone fibres: a correlative study of the growth and maturation of central and peripheral segments of large and small fibre classes. Prog Neurobiol 31:199-239.

Gauthier GF, Ono RD, Hobbs AW (1984) Curare-induced transformation of myosin pattern in developing skeletal muscle fibers. Dev Biol 105:144-154.

Genc B, Ozdinler PH, Mendoza AE, Erzurumlu RS (2004) A chemoattractant role for NT-3 in proprioceptive axon guidance. PLoS Biol 2:e403.

Guth L, Samaha FJ (1970) Procedure for the histochemical demonstration of myosin ATPase. Exp Neurol 28:365-367.

Hall JA, Oppenheim RW, Schachat FH (1988) Changes in myosin and 
c-protein isoforms proceed independently of the conversion to singly innervated neuromuscular junctions in developing pectoral muscle. Dev Biol 130:591-598.

Hamburger V, Oppenheim RW (1982) Naturally occurring neuronal death in vertebrates. Neurosci Commentaries 1:39-55.

Henneman E, Mendell LM (1981) Functional organization of the motoneuron pool and its inputs. In: Handbook of physiology, Vol 2, The nervous system, motor control, pp 423-507. Bethesda: American Physiological Society.

Hoke A, Ho T, Crawford TO, LaBel C, Hilt D, Griffin JW (2003) Glial cell line derived neurotrophic factor alters axon Schwann cell units and promotes myelination in unmyelinated nerve fibers. J Neurosci 23:561-567.

Houenou LJ, Pincon-Raymond M, Garcia L, Harris AJ, Rieger F (1990) Neuromuscular development following tetrodotoxin-induced inactivity in mouse embryos. J Neurobiol 21:1249-1261.

Jacob DA, Bengston CL, Forger NG (2005) Effects of Bax gene deletion on muscle and motoneuron degeneration in a sexually dimorphic neuromuscular system. J Neurosci 25:5638-5644.

Jacobson M (1991) Developmental neurobiology. New York, Plenum.

Jin TE, Witzemann V, Brecht M (2004) Fiber types of the intrinsic whisker muscle and whisking behavior. J Neurosci 24:3386-3393.

Keller-Peck CR, Feng G, Sanes JR, Yan Q, Lichtman JW, Snider WD (2001) Glial cell line-derived neurotrophic factor administration in postnatal life results in motor unit enlargement and continuous synaptic remodeling at the neuromuscular junction. J Neurosci 21:6136-6146.

Kinugasa T, Ozaki S, Hamanaka S, Kudo N (2002) The effects of sciatic nerve axotomy on spinal motoneurons in neonatal Bax-deficient mice. Neurosci Res 44:439-446.

Knudson CM, Tung KS, Tourtellotte WG, Brown GA, Korsmeyer SJ (1995) Bax-deficient mice with lymphoid hyperplasia and male germ cell death. Science 270:96-99.

Kong J, Xu Z (1998) Massive mitochondrial degeneration in motor neurons triggers the onset of ALS in mice expressing a mutant SOD1. J Neurosci 18:3241-3250.

Kozeka K, Ontell M (1981) The three-dimensional cytoarchitecture of developing murine muscle spindles. Dev Bio 87:133-147.

Kucera J, Walro JM (1992a) Formation of muscle spindles in the absence of motor innervation. Neurosci Lett 145:47-50.

Kucera J, Walro JM (1992b) Superfluousness of motor innervation for the formation of muscle spindles in neonatal rats. Anat Embroyl (Berl) 186:301-309.

Landmesser L (1992) The relationship of intramuscular nerve branching and synaptogenesis to motoneuron survival. J Neurobiol 23:1131-1139.

Matthews PB (1981) Muscle spindles: their messages and their fusimotor supply. In: Handbook of physiology, Vol 2, The nervous system, motor control, pp 189-228. Bethesda: American Physiological Society.

McHanwell S, Biscoe TJ (1981) The size of motoneurons supplying hindlimb muscles in the mouse. Proc R Soc Lond B 213:201-216.

Milburn A (1973) The early development of muscle spindles in the rat. J Cell Sci 12:175-195.

Misgeld T, Burgess RW, Lewis RM, Cunningham JM, Lichtman JW, Sanes JR (2002) Roles of neurotransmitter in synapse formation: development of neuromuscular junctions lacking choline acetyltransferase. Neuron 36:635-648.

Nave KA, Salzer JL (2006) Axonal regulation of myelination by neuregulin 1. Curr Opin Neurobiol 16:492-500.

Nemeth PM (1990) Metabolic fiber types and influences on their transformation. In: The segmental motor system (Binder M, Mendell L, eds), pp 258-277. New York: Oxford UP.

Nguyen QT, Parsadanian AS, Snider WD, Lichtman JW (1998) Hyperinnervation of neuromuscular junctions caused by GDNF overexpression in muscle. Science 279:1725-1729.

Okada A, Furber S, Okada N, Homma S, Oppenheim RW (1989) Synapse formation on motoneurons following the reduction of cell death by neuromuscular blockade. J Neurobiol 20:219-233.

Oppenheim RW (1984) Cell death of motoneurons in the chick embryo spinal cord: motoneurons prevented from dying in the embryo persist after hatching. Dev Biol 101:35-39.

Oppenheim RW (1991) Cell death during development of the nervous system. Annu Rev Neurosci 14:453-501.

Oppenheim RW (1996) Neurotrophic survival molecules for motoneurons: an embarrassment of riches. Neuron 17:195-197.
Oppenheim RW, Chu-Wang IW (1983) Aspects of naturally occurring motoneuron death in the chick spinal cord during embryonic development. In: Somatic and autonomic nerve-muscle interactions (Burnstock G, ed), pp 57-107. Amsterdam: Elsevier.

Oppenheim RW, Houenou L, Rieger F, Pincon-Raymond M, Powell JA, Standish JL (1986) The development of motoneurons in the embryonic spinal cord of the mouse mutant, muscular dysgenesis (mdg). Dev Biol 114:426-436.

Oppenheim RW, Bursztajn S, Prevette D (1989) Acetylcholine receptors and synaptogenesis in skeletal muscle following the reduction of cell death by neuromuscular blockade. Development 107:331-341.

Oppenheim RW, Houenou LJ, Parsadanian AS, Prevette D, Snider WD, Shen LY (2000) Glial cell line-derived neurotrophic factor and developing mammalian motoneurons: regulation of programmed cell death among motoneuron subtypes. J Neurosci 20:5001-5011.

Oppenheim RW, Calderó J, Cuitat D, Esquerda J, Ayala V, Prevette D, Wang S (2003) Rescue of developing spinal motoneurons from programmed cell death by the $\mathrm{GABA}_{\mathrm{A}}$ agonist muscimol acts by blockade of neuromuscular activity and increased intramuscular nerve branching. Mol Cell Neurosci 22:331-343.

Patel TD, Kramer I, Kucera J, Niederkofler V, Jessell TM, Arber S, Snider WD (2003) Peripheral NT3 signaling is required for ETS protein expression and central patterning of proprioceptive sensory afferents. Neuron 38:403-416.

Pettmann B, Henderson CE (1998) Neuronal cell death. Neuron 20:633-647.

Pittman RH, Oppenheim RW (1978) Neuromuscular blockade increases motoneuron survival during normal cell death in the chick embryo. Nature 271:364-366.

Pittman RH, Oppenheim RW (1979) Evidence that a functional neuromuscular interaction is involved in the regulation of naturally occurring cell death and the stabilization of synapses. J Comp Neurol 187:425-466.

Rondi-Reig L, Lohof A, Dubreuil YL, Delhaye-Bouchaud N, Martinou JC, Caston J, Mariani J (1999) Hu-Bcl-2 transgenic mice with supernumerary neurons exhibit timing impairment in a complex motor task. Eur J Neurosci 11:2285-2290.

Sanchez MP, Silos Santiago I, Frisen J, He B, Lira SA, Barbacid M (1996) Renal agenesis and the absence of enteric neurons in mice lacking GDNF. Nature 382:70-73.

Semba K, Egger MD (1986) The facial "motor" nerve of the rat: control of vibrissal movement and examination of motor and sensory components. J Comp Neurol 247:144-158.

Serrano AL, Petrie JL, Rivero J, Hermanson JW (1996) Myosin isoforms and muscle fiber characteristics in equine gluteus medius muscle. Anat Rec 244:444-451.

Silva AJ (1997) Mutant mice and neuroscience recommendations concerning genetic background: Banbury conference on genetic background in mice. Neuron 19:755-759.

Sohal GS, Sickler DW (1986) Embryonic differentiation of fiber types in normal, paralyzed and aneural avian muscle. J Embryol Exp Morph 96:79-97.

Song A, Tracey DJ, Ashwell KW (1999) Development of the rat phrenic nerve and the terminal distribution of phrenic afferents in the cervical cord. Anat Embryol (Berl) 200:625-643.

Sun W, Oppenheim RW (2003) Response of motoneurons to neonatal axotomy in Bax-knockout mice. Mol Cell Neurosci 24:875-886.

Sun W, Gould TW, Vinsant S, Prevette D, Oppenheim RW (2003) Neuromuscular development after the prevention of naturally occurring neuronal death by Bax deletion. J Neurosci 23:7298-7310.

Tang J, Landmesser L (1993) Reduction of intramuscular nerve branching and synaptogenesis is correlated with decreased motoneuron survival. J Neurosci 73:3095-3103.

Taylor MD, Vancura R, Williams JM, Riekhof JT, Taylor BK, Wright DE (2001a) Overexpression of NT-3 in skeletal muscle alters normal and injury-induced limb control. Somatosens Mot Res 18:286-294.

Taylor MD, Vancura R, Patterson CL, Williams JM, Riekhof JT, Wright DE (2001b) Postnatal regulation of limb proprioception by muscle-derived NT-3. J Comp Neurol 432:244-258. 
Taylor MD, Holdeman AS, Weltmer SG, Ryals JM, Wright DE (2005) Modulation of muscle spindle innervation by neurotrophin-3 following nerve injury. Exp Neurol 191:211-222.

Terrado J, Burgess RW, DeChiara T, Yancopoulas G, Sanes JR, Kato AC (2001) Motoneuron survival is enhanced in the absence of neuromuscular junction formation in embryos. J Neurosci 21:3144-3150.

Tourtellotte WG, Keller-Peck C, Milbrandt J, Kucera J (2001) The transcription factor Egr3 modulates sensory axon-myotube interactions during muscle spindle morphogenesis. Dev Biol 232:388-399.

Vogel M, Landmesser L (1987) Distribution of fiber types in embryonic chick limb muscle innervated by foreign motoneurons. Dev Biol 119:481-495.

Vult von Steyem F, Martinor V, Rabben I, Nja A, deLapeyriere O, Lomo T (1999) The homeodomain transcription factors islet 1 and HB9 are ex- pressed in adult alpha and gamma motoneurons identified by selective retrograde labeling. Eur J Neurosci 11:293-2102.

White FA, Keller-Peck CR, Knudson CM, Korsmeyer SJ, Snider WD (1998) Widespread elimination of naturally occurring neuronal death in Baxdeficient mice. J Neurosci 18:1428-1439.

Whitehead J, Keller-Peck CR, Kucera J, Tourtellotte WG (2005) Glial cellline derived neurotrophic factor-dependent fusimotor neuron survival during development. Mech Dev 122:27-41.

Wright DE, Zhou L, Kucera J, Snider WD (1997) Introduction of a neurotrophin-3 transgene into muscle selectively rescues proprioceptive neurons in mice lacking endogenous neurotrophin-3. Neuron 19:503-517.

Zelena J (1994) Nerves and mechanoreceptors: The role of innervation in the development and maintenance of mammalian mechanoreceptors. London: Chapman and Hall. 